\title{
Map of Retinal Position Onto the Cross Section of the Optic Pathway of Goldfish
}

\author{
R. BERNHARDT AND S.S. EASTER, JR.
}

Department of Biology, University of Michigan, Ann Arbor, Michigan 48109-1048

\begin{abstract}
The position of a retinal cell is defined by the two polar coordinates: $r$, the distance from the optic disc, and $\theta$, the angular (or clock-face) position. Axons of similar $\theta$ value were labeled by the punctate application of horseradish peroxidase (HRP) to optic axons in the retina, and axons of similar $\mathrm{r}$ value were labeled by the application of this same marker to a tectal fascicle. Labeled axons were traced in serial transverse sections of the optic pathway from the retina to the tectum to learn the map of the retinal surface onto the cross section of the pathway. Retinas were flat-mounted and treated for HRP to show the retinal origins of the labeled axons.

Axons of similar $r$ were clustered together, and the fraction of the pathway's cross-sectional area occupied by the cluster was about the same as the fraction of the retinal area occupied by the group of labeled somata. Axons of similar $\theta$ were also clustered, but the fraction of the cross-sectional area they occupied was larger than the fraction of retinal area occupied by their somata. The geometry of the clusters of labeled axons depended on the proximodistal location in the pathway. Near the retina both were stripshaped, but the location and orientation of the strip varied. Both an r-strip and a $\theta$-strip were labeled in some pathways by dual applications of HRP; the two strips were mutually orthogonal at all levels.

Each of $r$ and $\theta$ mapped onto a separate axis. The axons from most peripheral retina (largest $r$ ) were everywhere adjacent to the pia, and axons of progressively more central retina (smaller $r$ ) were progressively more separated from the pia (except in the nerve, where the secondary fasciculation complicates the geometry by wrapping old axons in new pia). The map of the circular variable, $\theta$, onto a line, required a discontinuity, the location of which differed, depending on the proximodistal level. From the retina to the chiasm, the discontinuity was at the ventral retinal radius (i.e., the right retinal clock-face positions were ordered 6-9-12-3-6 o'clock across the line); just central to the chiasm, the fibers reordered to put the discontinuity at the nasal radius (clock-face positions ordered 3-6-9-12-3); at the brachial bifurcation, the 3-6-9 half turned dorsally, the 9-12-3 half, ventrally.

The results are discussed in the context of the growth of the pathway and compared with similar organizational plans in the optic pathways of other vertebrates.
\end{abstract}

Key words: optic nerve, optic tract, axonal outgrowth, fiber order, visual system

The axons of neighboring retinal ganglion cells terminate at neighboring sites in the optic tectum (see Gaze, '70). The issue of whether the axons that begin and end near one another also course together in the optic pathway has received considerable attention in the past few years (Horder and Martin, '78; Scholes, '79; Rusoff and Easter, '80; Easter et al., '81; Bunt, '82; Bunt and Horder, '83; Easter, '85; Springer and Mednick, ' $85 \mathrm{~b}$, ' $86 \mathrm{~b}, \mathrm{c})$. The usual approach has been to label a group of axons at some point along the pathway and then to track them in cross sections, or whole mounts, or both.

The position of a ganglion cell in the retina (schematized as a plane) can be defined by the polar coordinates: $r$, the radial distance from the optic disc, and $\theta$, the angular or

Accepted June 24, 1986. 
clock-face position. In the cross section of the ribbon-shaped nerves of cichlid fish, the $r$ and $\theta$ coordinates map into the long and short dimensions of the ribbon, respectively (Scholes, '79). This organization was readily interpreted in the context of growth, as it was known that new generations of ganglion cells were continually added at the retinal margin, so the r-value of a ganglion cell indicates its age (larger $r$, younger age). Apparently, each new generation of axons grew in together, adjacent to the previous generation. The tendency of axons of similar $\theta$ to cluster together was attributed to their direct growth toward the point of exit from the retina-each new axon would tend to elongate in contact with other axons from the same sector.

In geometric terms, both $\mathrm{r}$ and $\theta$ are equally important to the description of the retinal position. But in goldfish optic nerve, several lines of evidence suggest that $r$ is the more important, in that axons of similar $r$ cluster more tightly than those of similar $\theta$. For example, when a bundle of axons was labeled by inserting a pin coated with horseradish peroxidase (HRP) into the nerve, the pattern of labeled retinal ganglion cells was always annular, and never sectoral (Rusoff and Easter, '80). Partial optic nerve section, followed by intraocular injection of tritiated proline, produced tectal autoradiograms with silver grains missing from an annular region of the tectal neuropil (Easter et al., '81), consistent with the idea that the severed axons had originated in an annulus. When fascicles of optic axons were labeled intratectally, partial annuli, and never sectors, were labeled retrogradely in the retina (Stuermer and Easter, ' $84 \mathrm{~b}$ ). Evidence that axons of similar $\theta$ cluster together has come from punctate intraretinal labeling of a small sector of axons on their spokelike trajectories to the disc. In the nerve and tract, the labeled axons were clustered (Easter et al., '81; Bunt, '82; Bunt and Horder, '83; Springer and Mednick, ' $85 \mathrm{~b}$, ' $86 \mathrm{~b}, \mathrm{c}$ ). This result seems to suggest that intranerve application (Rusoff and Easter, '80) ought to have labeled sectors of retinal cells, and prompted Springer and Mednick ('85a,b, ' $86 \mathrm{~b}, \mathrm{c}$ ) to question the conclusion that axons of similar $r$ were clustered.

These uncertainties can be removed only by a systematic study. Accordingly, we have labeled axons of common $\theta$, or axons of common $r$, or two groups, one of common $r$, the other of common $\theta$. We conclude that axons of common $r$ tend to cluster more tightly than axons of common $\theta$, even when both populations originate from retinal areas of comparable size. We describe how $\mathbf{r}$ and $\theta$ are represented in the optic nerve, tract and brachia (the two branches of the tract that encircle the tectum like the arms of a caliper), and we examine how the fiber topography relates to the order in which the axons exit from the brachium into the tectum. A preliminary account of this work has been published as an abstract (Bernhardt and Easter, '85).

\section{MATERIALS AND METHODS}

Adult goldfish of $7.0-10.0 \mathrm{~cm}$ standard length were kept in aerated 10 -gal tanks at room temperature $\left(20-27^{\circ} \mathbf{C}\right)$. All surgery was performed on fish deeply anesthetized by immersion in $0.2 \%$ tricaine methanesulfonate. The results are drawn from 40 fish, labeled as follows: retina alone $(\mathrm{N}=$ $14)$, tectum alone $(N=6)$, nerve alone $(N=6)$, retina and tectum $(\mathrm{N}=12)$, and retina and nerve $(\mathrm{N}=2)$.

\section{Retinal applications: Sectoral labels}

A small pellet of Gelfoam (Upjohn) was soaked in a solution of HRP (Miles Laboratories) and allowed to dry onto the tip of an insect pin. After cutting the skin around the orbit, the eye was slightly deflected and a small hole was made in the sclera. A pin was pushed through this incision into the vitreous, and was followed by the dried pellet, which expanded upon contact with the vitreous and remained inside the eye. This retrogradely labeled the somata of ganglion cells occupying part of a sector, approximately $5^{\circ}$ to $10^{\circ}$ wide, stretching from the lesion site to the retinal periphery (Fig. 4A). The addresses of the labeled somata have a wide range of values of $r$, but similar values of $\theta$. The central portions of the axons of these cells were labeled anterogradely. Axons originating in a sector will be referred to as a $\Theta$-group.

\section{Tectal applications: Partial annular labels}

To apply HRP to the tectum we used a method described previously (Stuermer and Easter, ' $84 \mathrm{~b}$ ). Briefly, the roof of the cranium was removed, one fascicle (or several) on the dorsal tectal surface was (were) severed with a fine needle, and a small pellet of HRP-soaked Gelfoam was put on the lesion site for several minutes, removed, and the skull was sealed shut. This procedure retrogradely fills axons of ganglion cell somata in a partial annulus; they share the same radial distance, $r$, from the optic disc, but extend through different values of $\theta$ (Fig. 2A). The partial annulus always extends from the nasal pole of the retina toward, and sometimes into, the ventrotemporal quadrant; its subtense depends upon where along its length the tectal fascicle was labeled. The more rostral the label site, the greater was the subtense. We have interpreted this variability as evidence that temporal axons leave the fascicle most rostrally to innervate the tectum, and progressively more nasal axons leave more caudally (Stuermer and Easter, '84b). Axons arising from such a partial annulus will be called an $r$ group. Because the goldfish retina grows by the addition of new ganglion cells at the periphery (Johns, '77), the cells in a common annulus have the same age.

\section{Nerve applications: Partial annular labels}

An HRP-coated needle was inserted into the nerve, intraorbitally, in much the same fashion as the retinal application. This labels a retinal annulus of larger subtense than the tectal application (Rusoff and Easter, '80).

\section{Dual applications: Sectoral and partial annular labels}

HRP was applied to both the retina and the tectum or to the nerve and the tectum as described above, in the same fish. Such applications permitted tracing of an r-group and a $\Theta$-group in the same pathway.

\section{Histochemistry}

Four days after the application of HRP, the fish were anesthetized and perfused through the heart with saline containing $1 \%$ sodium nitrite, followed by fixative ( $3 \%$ glutaraldehyde in $0.1 \mathrm{M}$ phosphate buffer, $\mathrm{pH}$ 7.4). The darkadapted retinae were isolated after exsanguination but prior to fixation, flat-mounted on a gelatin-coated microscope slide, and fixed (Easter et al., '81). Following the perfusion, the optic nerve, tract, diencephalon, and midbrain were dissected free; and the nerve was detached. Then the two fragments (the nerve and the tract with the brain) were smbedded in gelatin/sucrose (see Easter et al., '81). Serial $40-\mu \mathrm{m}$ sections were cut on a freezing microtome, at angles roughly perpendicular to the pathway, as shown in Figure 


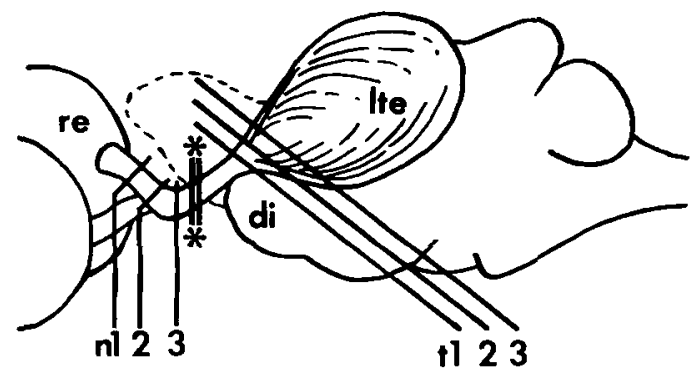

Fig. 1. Schematic of the goldfish brain, viewed laterally. Six prominent levels of sectioning are indicated: $n 1$, nerve near nerve head; $n 2$, intraorbital nerve; $n 3$, nerve near chiasm; $t 1$, tract before brachial split; $t 2$, brachia at level of the nucleus pretectalis superficialis pars magnocellularis; $\mathrm{t} 3$, tectal portion of dorsal brachium. The optic nerve was transected at the chiasm (between asterisks) and sectioned independently of the brain. The planes of section were chosen to cut the axons transversely. All cross sections are oriented with the viewer looking in the anterograde direction. re, right eye; lte, left tectum; di, diencephalon.

1 (compare also Springer and Mednick, ' $85 \mathrm{~b}$ ). The sections and whole-mounted retinae were incubated for HRP using diaminobenzidine with cobalt intensification (Adams, '81). The sections were lightly counterstained with methylene green.

This HRP procedure stains axons darkly but, regrettably, also stains endothelial cells and erythrocytes. While these are easily distinguished from labeled axons in the microscope, they are often not so easily distinguished in photomicrographs. Accordingly, we illustrate the data with photomicrographs whenever possible, and point out the spuriously labeled structures. In some cases, the sections are illustrated by camera lucida drawings.

Frozen sections destined for semithin sectioning were treated floating, washed in $0.1 \mathrm{M}$ phosphate buffer, osmicated ( $1 \% \mathrm{OsO}_{4}$ in $0.1 \mathrm{M}$ phosphate buffer, for 1 hour), dehydrated, cleared, and transferred into Epon. Blocks containing flattened sections were obtained by embedding the tissue in a few drops of Epon between two plastic coverslips. Semithin sections, 1-2 $\mu \mathrm{m}$ thick, were cut and counterstained with toluidine blue.

\section{Morphometry}

Areas of sections and retinae in calibrated photomicrographs and camera lucida drawings were measured on a digitizing pad (Zeiss MOP-3).

\section{Conventions}

Although both sides of the visual system were used and examples of both appear in the figures, we describe the data always in terms of right eye-left tectum. Thus the retinal clock-face positions are referred to dorsal (12 o'clock), nasal (3), ventral (6), and temporal (9). A dorsal sector labeled intraretinally lies between 11:30 and 12:30; and nasal, temporal, and ventral sectors are analogously located. When we refer to quadrants, they have the following locations: dorsonasal (12-3), ventronasal (3-6), ventrotemporal (6-9), and dorsotemporal (9-12). It should be kept in mind that the distribution of retinal axons is not divided strictly along the 3 o'clock to 9 o'clock line as we and others had previously assumed, for Springer and Mednick ('86a) have shown that the dorsal and ventral brachia receive unequal shares of the retinal axons.

We use the terms "central" and "peripheral" to refer to retinal locations near to or far from the optic disc, respec- tively. The position along the pathway is described with reference to the brain; that is, proximal is toward the brain, distal toward the retina.

\section{RESULTS r-groups}

The organization of r-groups, studied after application of HRP to a single tectal fascicle, is discussed first. These data will illustrate the basic organization of the pathway and facilitate the interpretation of the dual-labeling experiments described subsequently. The description begins at the retina and proceeds proximally.

When the labeled somata were restricted to the ventronasal quadrant (Fig. 2A), the labeled axons clustered on the nasal side of the nerve (Fig. 2B). The cluster was often partitioned in several adjacent fascicles, but in the tract it became strip-shaped (Fig. 2C) and remained so in the dorsal brachium, as illustrated in Figure 2D,E.

When the labeled somata lay in both ventronasal and ventrotemporal quadrants, as they did when the tectal fascicle was labeled at a very rostral position (explained in Materials and Methods), then the nerve contained two clusters of labeled axons, one nasal and one temporal. One such case is shown in Figure 4A,B, and it will be discussed in detail below, but two points warrant mention here. First, the bipartite $r$-group is consistent with earlier work (Easter et al., '81) which showed that ventral retinal axons split in two groups in the nerve (see Fig. 3B,E) flanking the dorsal retinal axons that coursed in the nerve's center. Second, the two groups in the nerve merged to form a single group more proximally, and it behaved much like the one shown in Figure 2C-E.

\section{O-groups}

The group of axons labeled by an intraretinal application of HRP was also strip-shaped but looked very different from the r-group in two respects. First, near the eye, the $\theta$-group was oriented dorsoventrally and always touched the ventral side of the nerve (Fig. 3A-C). Since the intraretinal application labels all axons that originated peripherally to the site of application, this is consistent with the earlier conclusion that the new axons are added to the ventral edge of the nerve (Easter et al., '81, '84; Bunt, '82). Second, the $\Theta$-group dispersed much more widely than the r-group. A comparison of Figure 3D-F with Figure $2 \mathrm{C}$ will illustrate this point, but it is made more strongly in the next section, a description of doubly labeled pathways.

\section{$\theta$ - and r-groups}

Both groups are seen in those pathways labeled in both the retina and the tectum. Figures $4-8 \mathrm{~A}$ illustrate a series of sections taken from one dually labeled fish. The retina is shown in Figure 4A; a ventronasal partial annulus and a temporal sector had been labeled, occupying $3.5 \%$ and $2.2 \%$ of the total retinal area, respectively. Figures $4 \mathrm{~B}-8 \mathrm{~A}$ show sections taken through the corresponding nerve, tract, and brachia, at increasing distances from the eye. Near the nerve head (Fig. 4B) the r-group occupied $2.6 \%$ of the crosssectional area of the nerve, and at successively more central levels (Figs. 4C,D, 5,6) this percentage did not vary significantly.

In contrast, the cross-sectional area occupied by the $\theta$ group varied, from $12 \%$ near the nerve head (Fig. 4B) to approximately $30 \%$ (Fig. 4C,D), $40 \%$ (Fig. 5A,B), 50\% in the distal tract (Fig. 5C,D), and $16 \%$ in the proximal tract (Fig. 

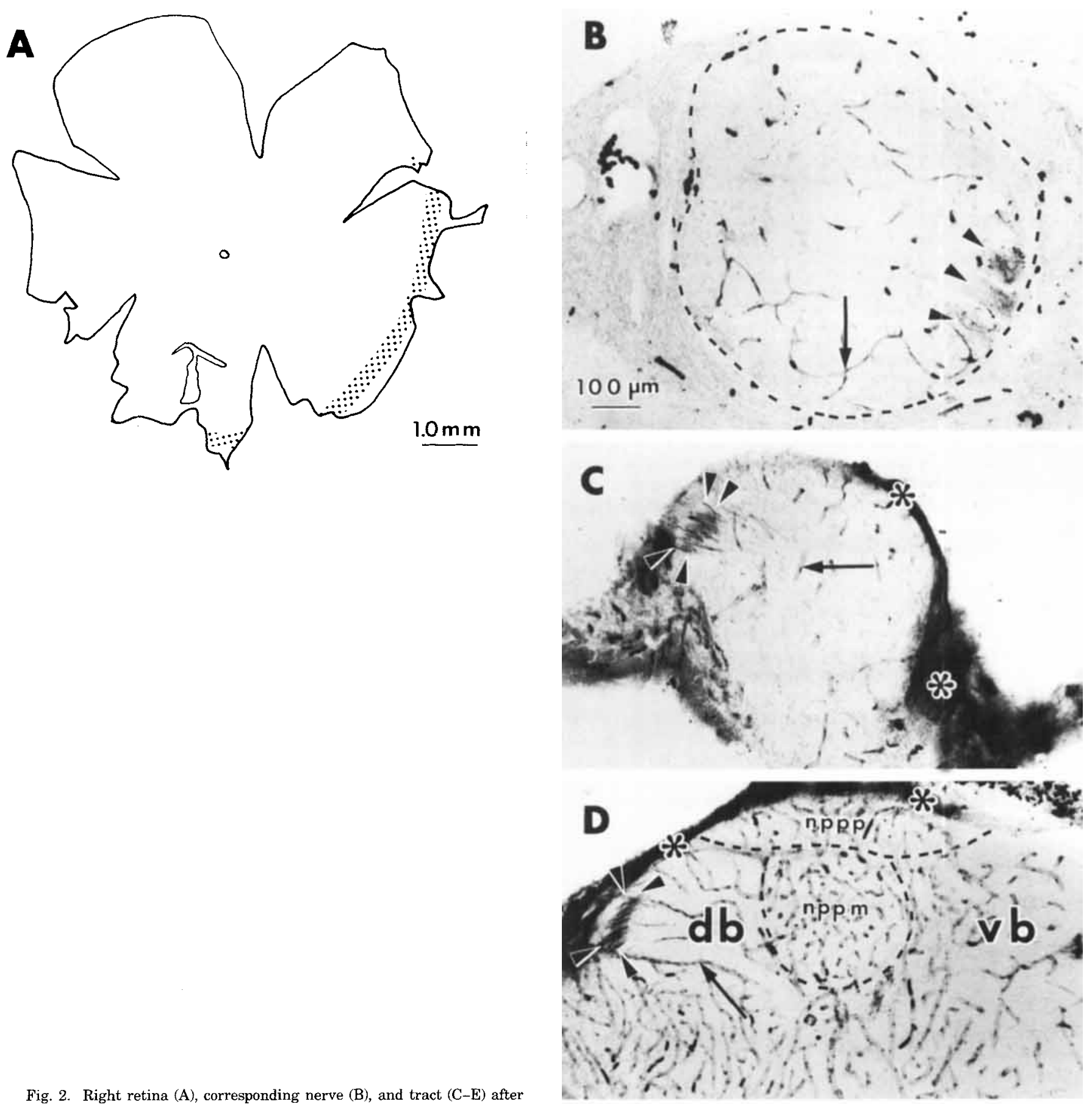

Fig. 2. Right retina (A), corresponding nerve (B), and tract (C-E) after application of horseradish peroxidase (HRP) to a tectal fascicle. Arrows and asterisks indicate nonspecific reaction in blood vessels and pia, respectively. Magnification for micrographs $\mathrm{B}-\mathrm{E}$ as indicated in $\mathrm{B}$.

A. Camera lucida tracing of the whole-mounted retina. Zone of labeled somata is indicated by shading. Dorsal is up, nasal to the right. $B$. Intraorbital nerve (n2) (outlined). Labeled axons are indicated by arrowheads. Same orientation as A. C. Tract ( $\mathrm{t} 1$ ). Labeled axons form one dense band, the r-group, (between arrowheads) aligned parallel to pial surface. Lateral is up, rostrodorsal to the left. D. Dorsal brachium (t2). The r-group (between arrowheads) extends parallel to the pial surface. Same orientation as C. nppp, nucleus pretectalis superficialis pars parvocellularis; nppm, nucleus pretectalis superficialis pars magnocellularis (previously called nucleus rotundus: see Braford and Northcutt ' 83 ), db, dorsal brachium; vb, ventral brachium. E. Dorsal brachium (t3). The r-band extends across the width of the brachium (between arrowheads), far from the tectum (te) and close to the torus longitudinalis (tl). Rostrodorsal is up, lateral to the right.

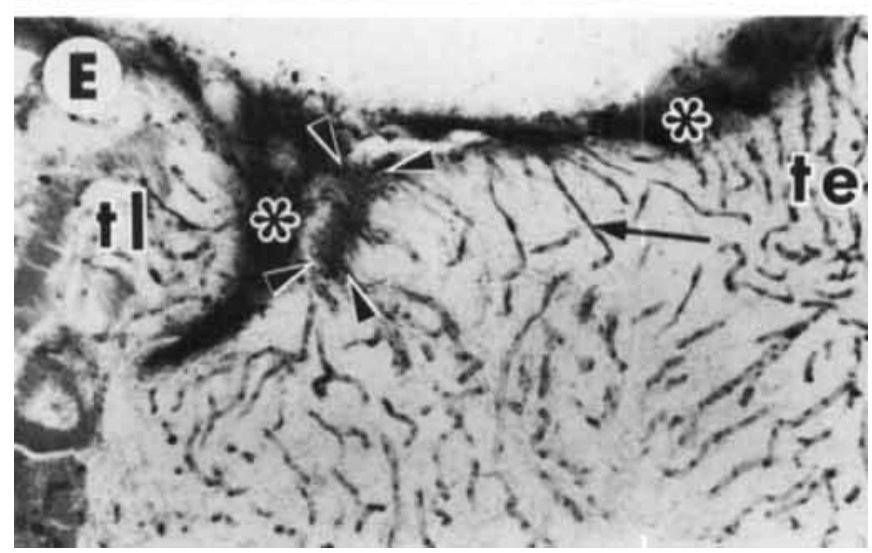




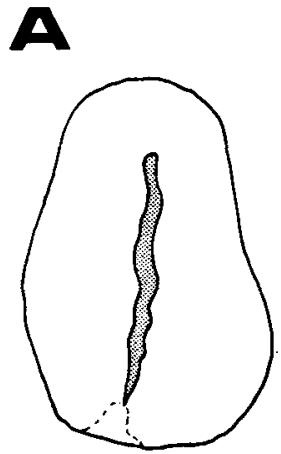

\section{DORSAL LESION}

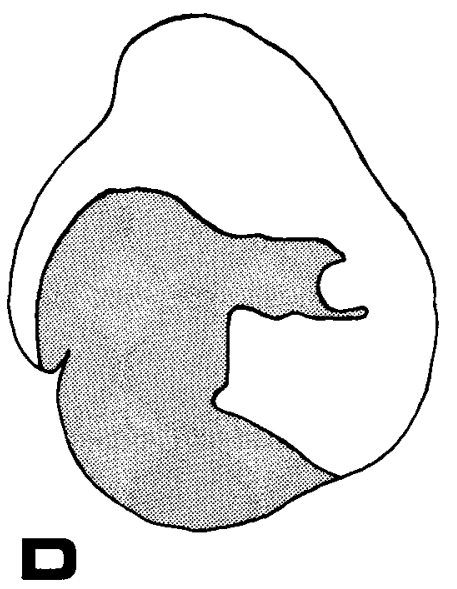

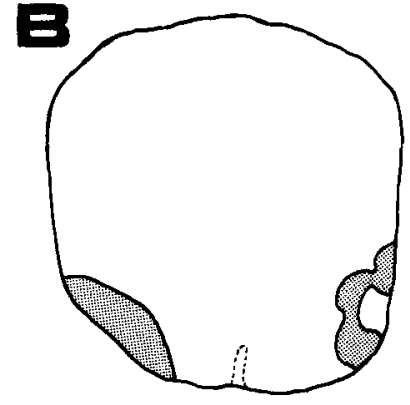

VENTRAL LESION

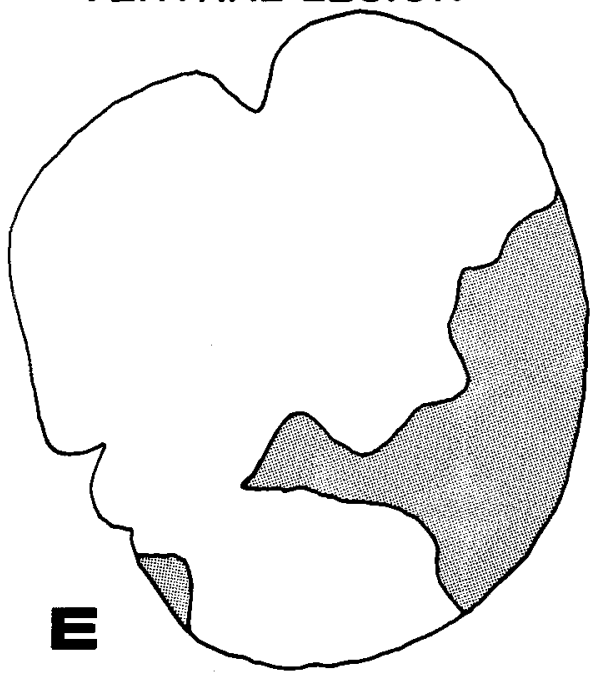

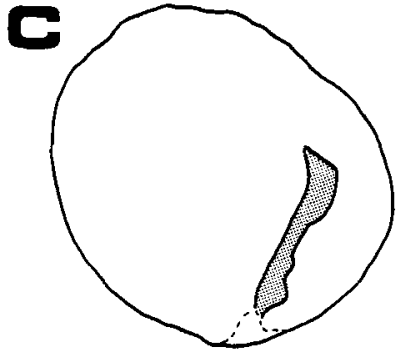

NASAL LESION

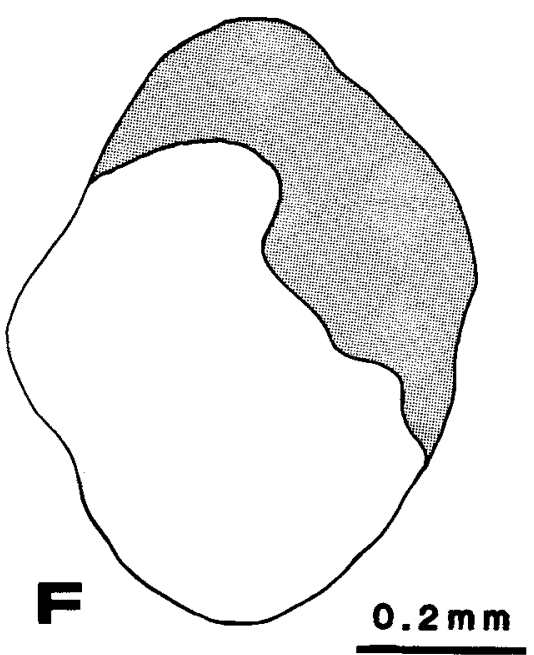

Fig. 3. Pairs (A,D; B,E; C,F) of camera lucida tracings, illustrating $\theta$ bands in three right optic nerves sectioned (A-C) near the nerve head (n1) and (D-F) in mid-orbit (n2). In A-C, a distinct glial intrusion (outlined by dotted line) associated with the intraorbital exit site of the ophthalmic artery, marks the ventral pole. Dorsal is up, mediorostral to the right.

7). Axons from all sectors dispersed approximately equally, as suggested by Figure 3 .

A quantitative comparison of the dispersion is given by the spread function, defined as the ratio: (percentage of pathway cross section occupied by labeled fibers/percentage of retinal area occupied by labeled somata). The smaller the number, the less is the dispersion. The spread function of the $\theta$-group in the nerve and tract just described varied distoproximally from $5.5(12 / 2.2)$ to $22.7(50 / 2.2)$ and back to $7.3(16 / 2.2)$. It was relatively constant for the $r$-group, about $0.7(2.6 / 3.5)$. It is unlikely that these differences in dispersion are due to loss or gain of labeled axons along the pathway, because we have counted labeled axons in semithin sections and found that the numbers were very nearly the same (within 25\% in both groups) near the retina and in the tract. We conclude that axons of similar $\theta$ tend to wander more, with respect to their original neighbors, than axons of common $r$.

The substructure of the two labeled populations differed, as shown in the semithin sections of Figure 9. The cross section of the mid-orbital nerve is separated into bundles. The axons in the r-group tended to be clustered in high density in these bundles, and nearby bundles had either a similarly high density or none (Fig. 9A). In contrast, the density of labeled fibers within the $\theta$-group was generally lower and more uniform across bundles (Fig. 9B).

\section{Map of $\Theta$ and $\mathbf{r}$}

Both singly and dually labeled fish were examined to learn how the retinal polar coordinates are represented in the cross section of the optic pathway. The results are described in the nerve, tract, and brachium, successively.

\section{Map in the nerve}

Near the retina, axons from different sectors occupied different and reproducible positions in the cross section of the nerve. Dorsal axons were found in the center (Fig. 3A), ventral axons on both sides (mediorostral and laterocaudal) (Fig. 3B), and nasal (Fig. 3C) and temporal axons (Fig. 4B) in intermediate positions. Clock-face position is thus mapped across the horizontal axis of the cross-sectioned nerve, as Scholes ('79) showed in cichlids, and as Easter et al. ('81) and Bunt ('82) suggested for goldfish.

This organization is also illustrated in sections of a nerve in which axons from a temporal sector and a ventronasal included the youngest but not the oldest somata (Fig. 4A), and near the nerve head (Fig. 4B), the $\theta$-group extended from the ventral edge towards, but not completely up to, the dorsal pole. This supports the idea (Scholes, '79; Easter et al., '81) that the coordinate, $r$, maps along the vertical axis of the distal nerve, with the central (oldest) axons at annulus had been labeled (Fig. 4). The group from the sector 

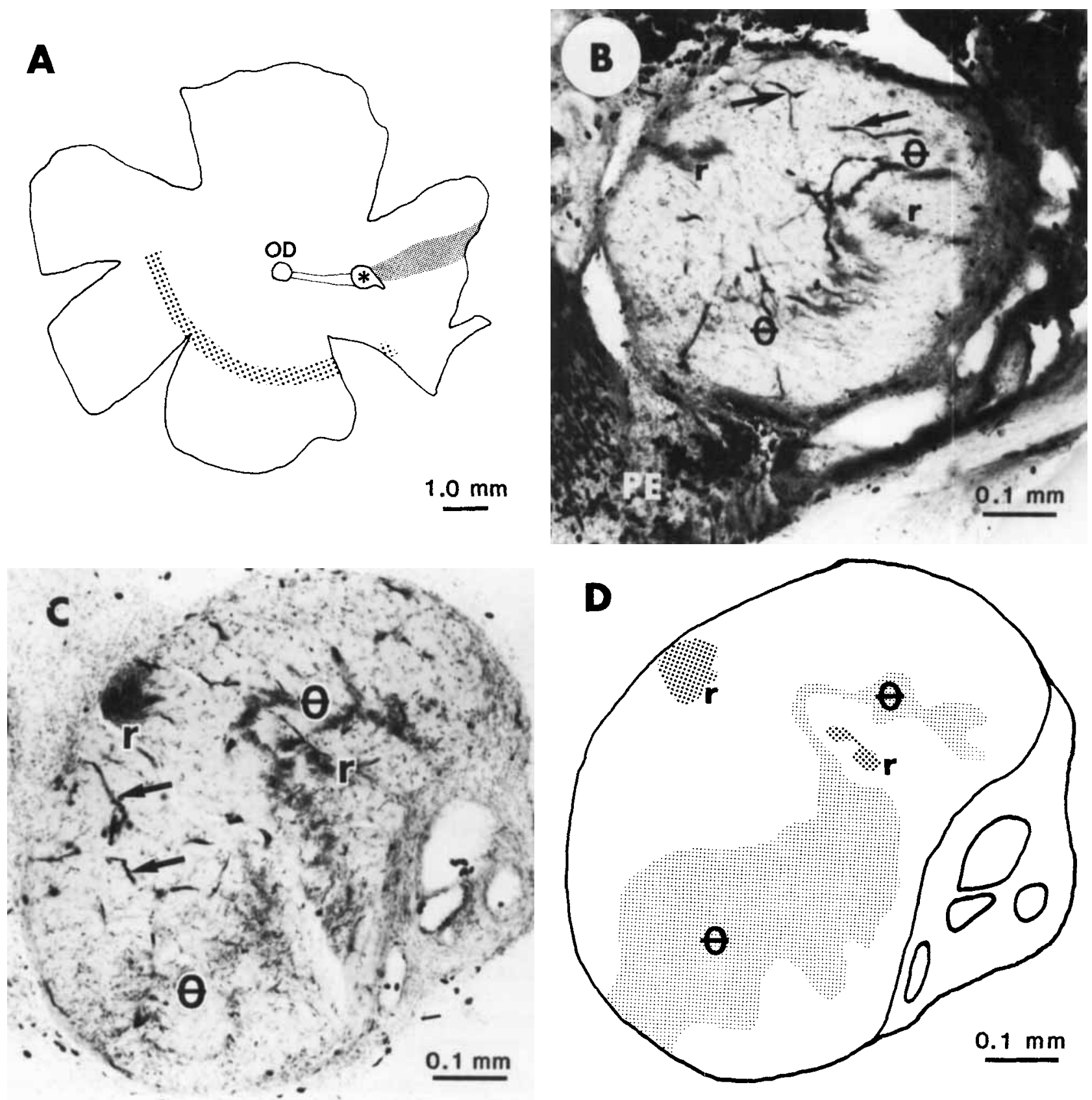

Fig. 4. Left retina (A) and corresponding intraorbital optic nerve (B-D) after labeling axons of common $\theta$ and $r$. Same orientation in all (dorsal up, rostral left). Reactivity in blood vessels (arrows) is nonspecific. A. Camera lucida tracing of the whole-mounted retina. Cell bodies in a narrow temporal sector (fine dots) and in a partial, ventronasal annulus (coarse dots) have been labeled by HRP. The asterisk marks the site of intraretinal application. OD, optic disc.

the dorsal edge. This was supported further by labeling partial retinal annuli of different radii. Axons from peripheral retina (Fig. 2A) were located more ventrally in the nerve (Fig. 2B) than axons from more central retina (Fig. 4A,B).

The $\theta$ - and $r$-bands were always mutually perpendicular (Fig. 4B) in support of the polar coordinate model (Scholes, '79; Easter et al. '81). More proximally, the two populations

B: Cross-sectioned optic nerve near the nerve head (n1). The $\theta$-group ( $\theta$ ) forms a dense band, stretching from ventral towards dorsal. The (ventronasal) r-group ( $r$ ) is split into two dense bands on both sides of the nerve. $\mathrm{PE}$, pigmented epithelium.

C, D. Micrograph (C) and corresponding camera lucida sketch (D) of a cross section through the intraorbital nerve (n2). The relative positions of the two groups of fibers are the same as near the nerve head.

remained roughly orthogonal to each other (Figs. 4-8), although this relation was somewhat masked by the dispersion of the axons of common $\theta$.

\section{Map in the tract}

The map changes abruptly over the most distal segment of the tract, roughly $500 \mu \mathrm{m}$ between the chiasm and $\mathrm{t} 1$ of Figure 1. The details of this change have recently been 

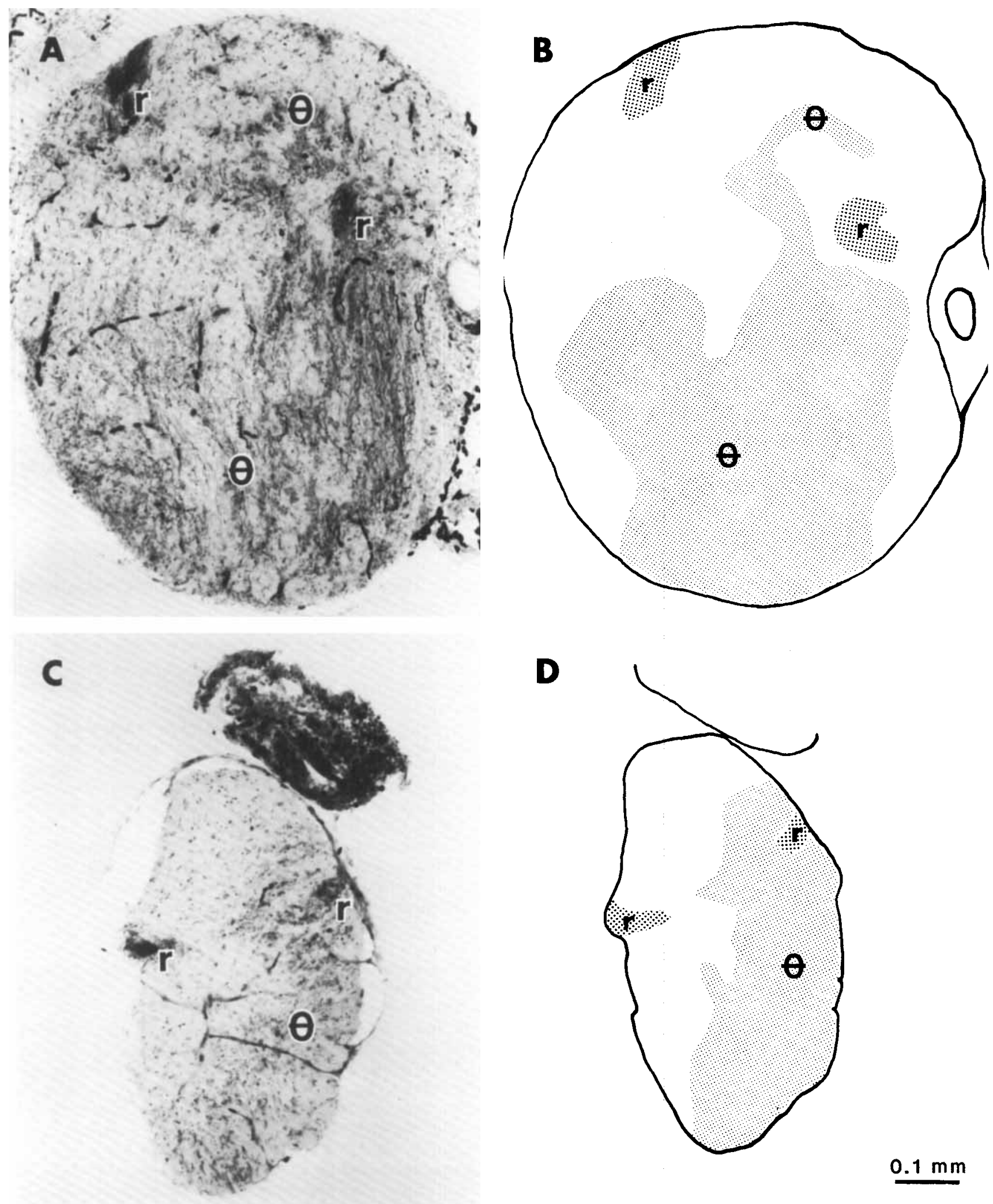

$0.1 \mathrm{~mm}$

Fig. 5. Micrographs $(A, C)$ and camera lucida tracings (B,D) of cross sections of optic nerve (A,B) and distal tract (C,D). Same animal as in Figure 4.

A, B. Optic nerve close to the chiasm (n3). The 0 -group has spread to occupy a large cross-sectional area, but the bipartite r-group remains com- pact. The relative positions of the two labeled bands have not changed (compare Fig, 4C,D) Same orientation as in Figure 4. C,D. Optic tract (distal to t1). The micrograph is aligned to facilitate comparison with Fig. ures $4,5 \mathrm{~A}, \mathrm{~B}$. The dark fragment above the tract is connective tissue. Orientation is roughly lateral, down, rostrodorsal, left. 

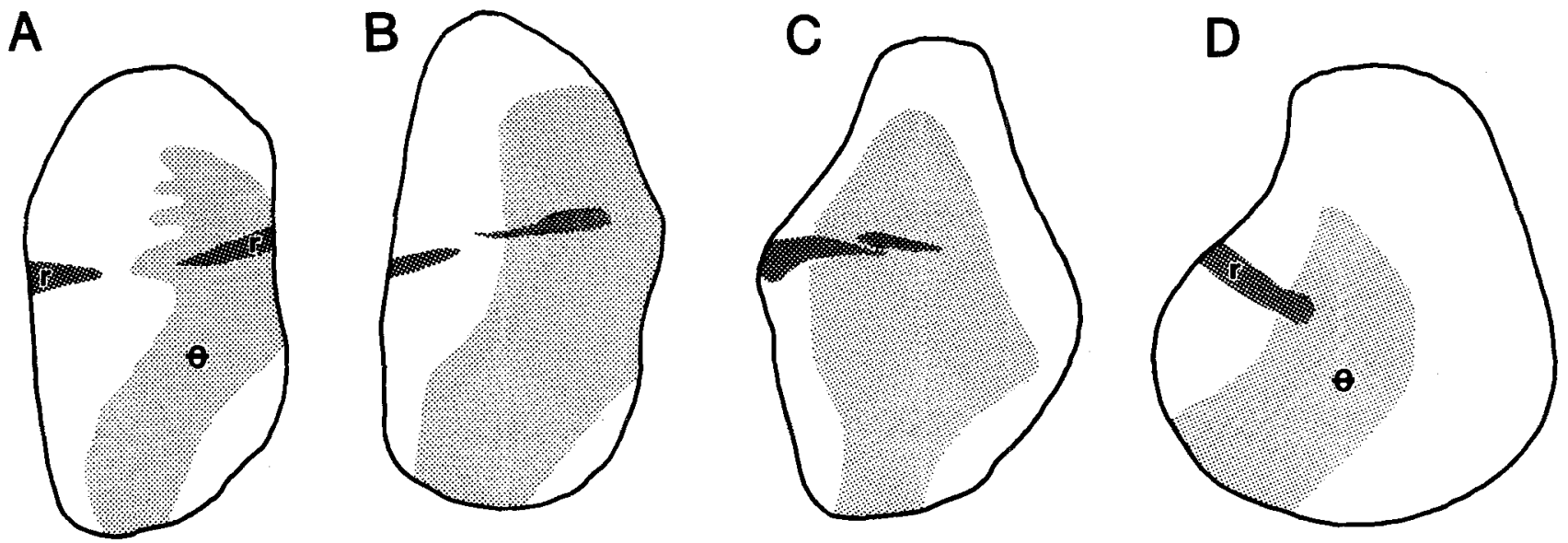

Fig. 6. A series of four camera lucida drawings, taken at about 100 - $\mathrm{km}$ intervals, illustrating the reordering of ventronasal axons in the distal tract. Same animal as in Figures 4 and 5 . The orientation is the same as in Figure 5C,D.

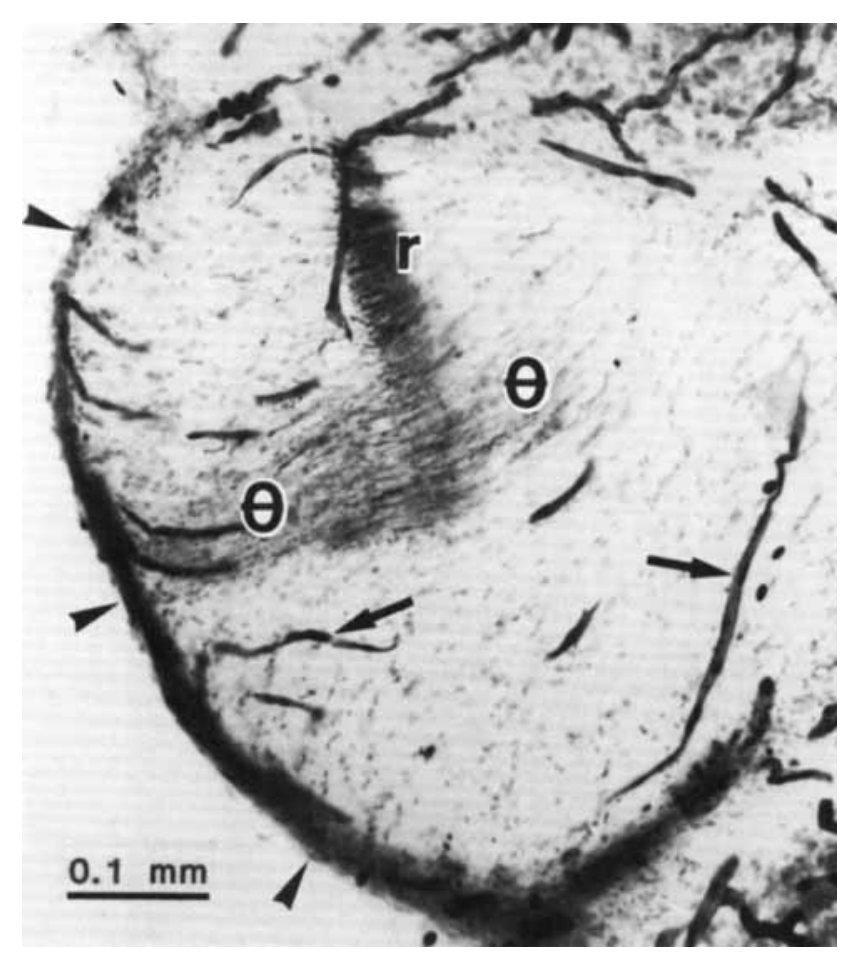

Fig. 7. Optic tract (t1), same animal as in Figures 4 and 5. Reaction in the pia (arrowheads) and in blood vessels (arrows) is nonspecific. Rostrodor sal is up, lateral to the left.

described very convincingly by Springer and Mednick ('86c), and we agree in nearly all respects. Our approach differed slightly from theirs, and gave some additional information, so we describe these results briefly.

In Figure 5A,B, from the nerve, the diffuse $\theta$-group envelops the small subband of the ventrotemporal fibers in the r-group (right side) but does not touch the ventronasal subgroup (left). More proximally, Figure 5C,D, from the tract, shows much the same pattern. Figure 6 shows, in four sections $100 \mu \mathrm{m}$ apart, the abrupt merger of the ventrotemporal axons of the r-group with the ventronasal axons of that same group. In the same sections, the temporal $\theta$ group moves from its position on the edge of the tract into the center. More proximally, where the tract runs along the diencephalon, the two groups remain mutually orthogonal (Fig. 7). The r-group is oriented parallel to the pia, the $\theta$ group, perpendicular. The reordering has segregated the nasoventral retinal axons to the rostrodorsal part of the tract (r-group in Fig. 7), the temporal axons to the center ( $\Theta$-group in Fig. 7), and the dorsal axons (unlabeled) to the caudoventral part. This anticipates the slightly more proximal bifuraction of the tract into the two brachia.

The shifts of Figure 6 confirm the rearrangements described by others (Scholes, '79; Bunt, '82; Springer and Mednick, ' $86 \mathrm{C}$ ), and extend them by showing that the rearrangements occur within an r-group. This is consistent with our understanding of how the pathway develops; the newest fibers, identified by their lack of myelin (Easter et al., '81) always occupied the superficial (pial) side of the tract. Each new generation of axons (r-group) is added at this location, and the reordering must occur as the axons grow in, within each generation of axons.

\section{Map in the brachia}

The fiber order near the tectum is of special interest because it has been suggested as the major determinant of the retinotectal map (Horder and Martin, '78).

The brachial map is best illustrated in those fish with dual applications of HRP; two examples are shown in Figure 8 . The $\theta$ - and r-groups occupied bands, similar but for the greater scatter in the $\theta$-band. The $\theta$-band was perpendicular, and the r-band parallel, to the pia. (Neither band extended through the full thickness of the brachium, and we assume that this occurred because neither method of application labeled all the cells in the relevant zone. That is, the retinal label always spared the most central cells of the sector, and the tectal application spared the temporal axons of the half annulus.) Our assumption is strongly supported in the case of the r-bands, as shown in Figure 10. The labeled axons in Figure 10 originated from a $270^{\circ}$ partial annulus at approximately $80 \%$ of the distance from 


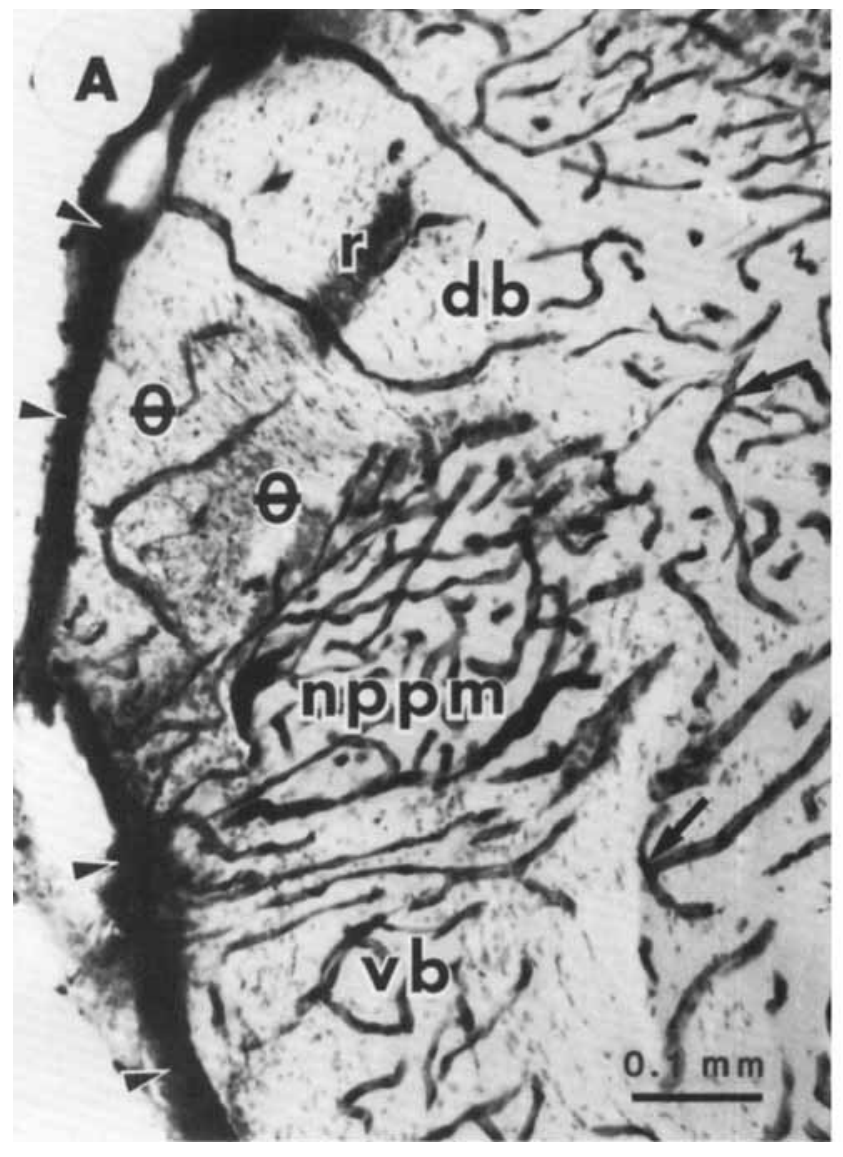

Fig. 8. Two sections through the brachia ( $t 2)$ of two doubly labeled fish Rostrodorsal is to the top. Reaction product in blood vessels (arrows) and pia (arrowheads) is nonspecific. vb, ventral brachium.

A. Right diencephalon. Same fish as Figures 4-7. The (ventronasal) $r$ band extends parallel to the pial surface, from the rostral pole of the dorsa

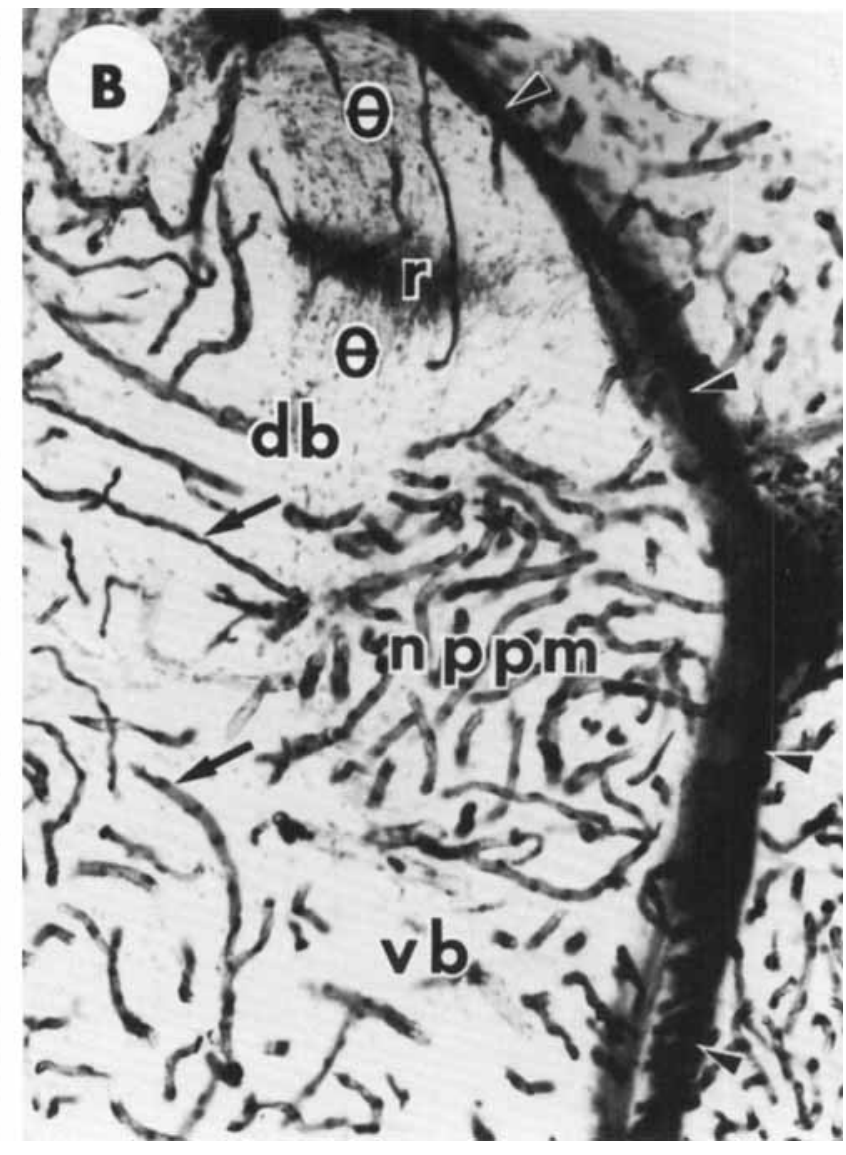

brachium (db) toward the center. Axons in the (temporal) $\theta$-band are more scattered. They run close to nppm and extend along the mediolateral axis of the brachium. Lateral is to the left. B. Left diencephalon. Different fish from Figures 4-8A. The (ventronasal) r-group forms a dense band, parallel to the pial surface. The (nasal) $\theta$-group is less compact, and oriented perpendicular to the r-band. Lateral is to the right.

peripheral of the two labeled tectal fascicles. Stuermer and Easter ('84b) have shown that axons in peripheral tectal fascicles originate from peripheral retina. Therefore, the axons closer to the pia can be assigned to somata in the more peripheral, and axons farther from the pia to the more central, retinal annulus. In summary, the vectors $r$ and $\theta$ mapped mutually orthogonally in the dorsal brachium, $\theta$ parallel to the pia, $r$ perpendicular to it.

The precision of this map was investigated quantitatively. The width of labeled partial annuli varied between $5 \%$ and $10 \%$ of the retinal radius (Figs. $4 \mathrm{~A}, 11 \mathrm{~A}, \mathrm{C}$ ). The corresponding r-bands occupied about $6-12 \%$ of the mediolateral extent of the brachium (Figs. 8A,B, 11C,D). The similarity of these percentages suggests that $r$ was mapped to scale, with little overlap between axons of different ages. In contrast, labeled retinal sectors occupied about $3-6 \%$ of the $180^{\circ}$ hemiretinal circumference, but the corresponding $\theta$-bands occupied $25-50 \%$ of the rostrocaudal extent of the brachium (Fig. 8A,B). These very different percentages in. dicate that $\theta$ was mapped imprecisely; axons originating from different sectors must have overlapped substantially. This conclusion was supported by dual tectal applications of HRP, which labeled two partial annuli of very different lengths and angular subtenses, in the same eye (Fig. 11A). The lengths of the two r-bands in the dorsal brachium were sponding dorsal brachia two bands of axons were labeled (Fig. 11B,D), and the peripheral band linked with the more 

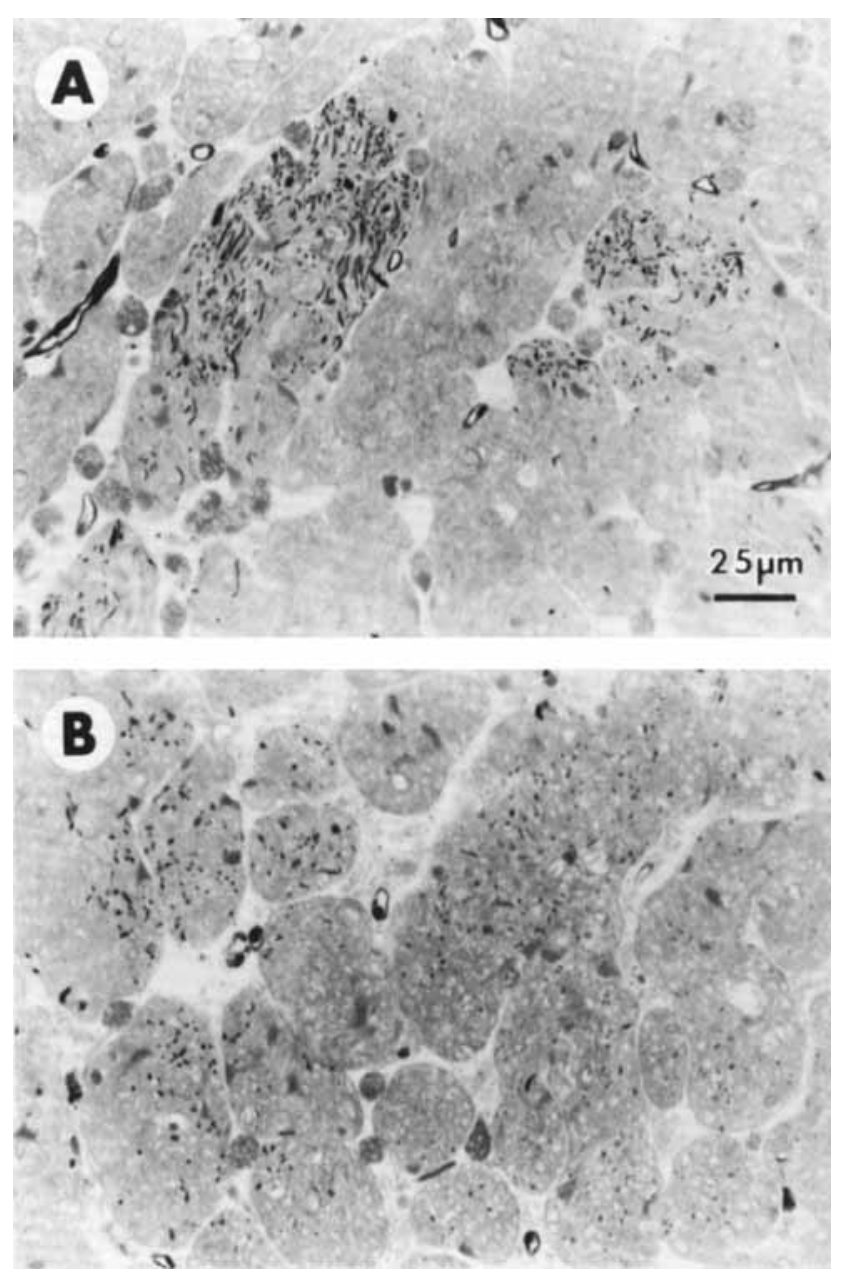

Fig. 9. Semithin section through the intraorbital nerve (n3) from a retina with a labeled temporal sector $(\theta)$ and nasoventral annulus (r). Orientation unspecified. Same magnification in both A and B. A. Detail of the r-band. B. Detail of the $\theta$-band.

similar (Fig. 11B), even though the more central band originated from a much shorter retinal arc. We conclude that the $\theta$-group is less well ordered than the r-group in the brachia, as it was in the nerve and tract.

\section{Axonal exits}

In the diencephalon, the tract begins to lose axons, which terminate in a variety of nuclei. The courses of the axons innervating diencephalic and pretectal targets have been described previously (Fraley and Sharma, '84, '85; Presson et al., '85) and were not examined in this study, which concentrated on the major target of the retinal axons, the optic tectum, innervated by axons from the brachia. Earlier work (Stuermer and Easter, ' $84 \mathrm{~b}$ ) concluded that axons exited from the brachia in temporonasal order; that is, temporal axons exited rostrally, successively more nasal axons more caudally. In the work to be described next, this conclusion is checked and we compare the brachial stratification with the order of exit.

The exit of the temporal axons is shown in Figure 12, from a fish with temporal fibers labeled intraretinally. They left the brachia immediately caudal to the nppm, and innervated rostral tectum, in a terminal zone that extended

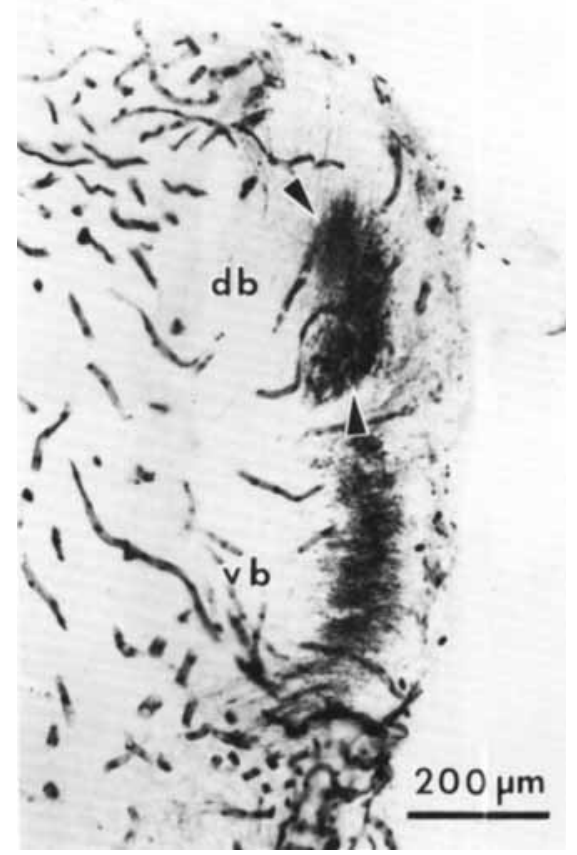

Fig. 10. Cross section of left tract (t1) of a fish in which a $270^{\circ}$ right retinal annulus, sparing only ventronasal retina, was labeled in the nerve. Rostrodorsal is up, lateral to the right. The $r$-band extends parallel to the pia through the ventral (vb) and most of the dorsal brachium (db). The most rostral portion of the dorsal brachium is not labeled; it contains ventronasal fibers.

from the rostral pole along the tectal equator (not shown). At more caudal levels in the brachia of this animal, there were no labeled axons, confirming the earlier conclusion (Attardi and Sperry, '63; Stuermer and Easter, '84b) that temporal axons exit first.

The subsequent course of the ventronasal axons is illustrated in Figure 13, which shows a pair of labeled r-bands that originated from two partial ventronasal annuli (Fig. 11C). In Figure 13A the labeled bands are oriented roughly parallel to the curved pial boundary on the lateral side of the tract. The labeled bands are incomplete; presumably unlabeled ventrotemporal axons of the same r-value complete the bands. More centrally (Fig. 13B) the two bands of labeled axons are oriented perpendicular to the pia. Moreover, they are contiguous with the pia, presumably because of the departure of the unlabeled ventrotemporal axons. The central retinal axons $(\mathrm{r} 1)$ are closer to the tectum while the more peripheral axons ( $(\mathrm{2} 2)$ are farther from it and closer to the torus longitudinalis. Figure 13C, taken at a slightly more proximal level, illustrates three points. First, the brachium is reduced in size, particularly in the direction perpendicular to the labeled bands. This is a result of the departure of fascicles of older axons from all clock-face positions (Stuermer and Easter, '84b; see Fig. 16B). Second, the orientation of the age bands, perpendicular to the pial surface, is maintained. Third, the groups of labeled axons are more distinctly isolated into discrete bundles here than at the more distal location.

The representation of sectoral order was studied after intraretinal labeling of ventral and nasal sectors. Axons of ventral retinal origin (Fig. 14B) preferentially occupied the superficial (piawards) half of the brachium, while axons of 

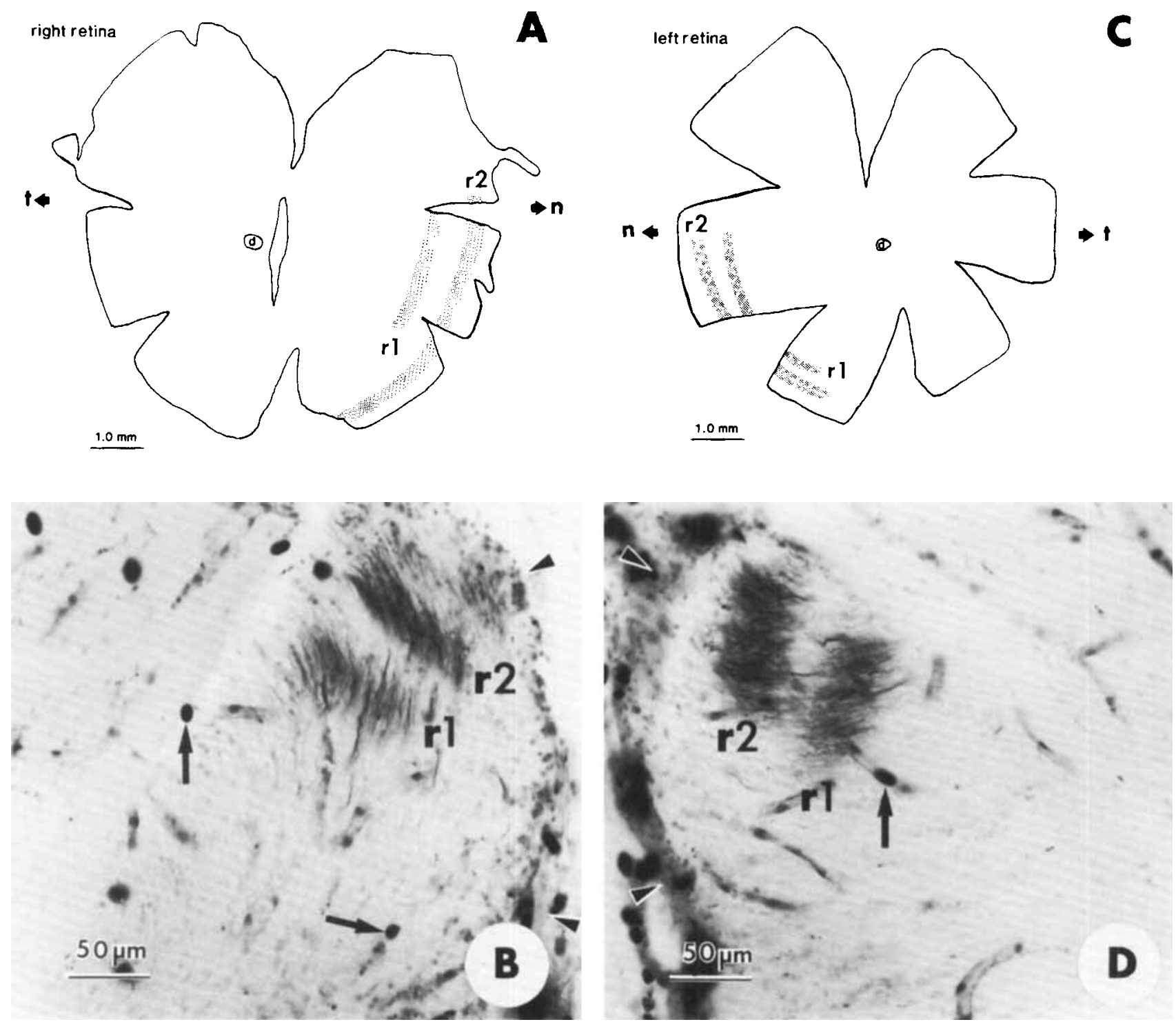

Fig. 11. Retinae and corresponding dorsal brachia after dual tectal applications. Reaction in erythrocytes (arrows) is nonspecific. A. Camera lucido drawing of a whole-mounted retina. Dorsal is to the top. Two labeled partial annuli, r1 and r2, subtend very different angles. d, optic disc; $n$, nasal; $t$, temporal. B. Cross section through the dorsal brachium (t2) contralateral to the retina in A. Medial is to the left, rostrodorsal up. HRP-reactive axons form two bands, $\mathrm{rl}$ and $\mathrm{r} 2$, of similar length, parallel to each other and to

nasal origin (Fig. 14A) were predominantly deeper. This suggests that axons exit into the tectum from the most superficial layer of the brachium, directly beneath the pia. Thus the stratification anticipates the temporonasal sequence of exit previously demonstrated (Stuermer and Easter, ' $84 b$ ).

To summarize, the disposition the $r$ - and $\theta$-groups in the brachia as it courses alongside the tectum is similar to more distal levels. The two dimensions map mutually orthogonally. The younger axons grow in along the outer boundary, separated by their predecessors from the tectum. In the other direction, there is a very rough layering of axons according to retinal origins, nasalmost deep, temporalmost superficial. the pial surface (arrowheads). C. Camera lucida drawing of another retinal whole mount. Dorsal is to the top. Two labeled partial annuli, r1 and $r 2$, subtend roughly equal angles. Abbreviations as in A. D. Cross section through the dorsal brachium (t2) contralateral to the retina in C. Medial is to the right, rostrodorsal up. Two bands of labeled axons, $r 1$ and $r 2$, have similar lengths.

\section{DISCUSSION}

Our observations and conclusions are summarized below.

1. Axons of common $r$ course together, as do those of common $\theta$. But the $\theta$-group disperses much more than the r-group, particularly intraorbitally.

2. The coordinates, $r$ and $\theta$, are mapped on two mutually orthogonal axes in the cross section of the optic pathway, from the eye to the tectum.

3. The mapping of the retinal circumference along one axis requires a discontinuity in $\theta$. In the nerve this discontinuity is at the ventral radius ( 6 o'clock). In the tract, fibers of different $\theta$-value exchange places, and the discontinuity shifts abruptly to the nasal radius ( 3 o'clock). 


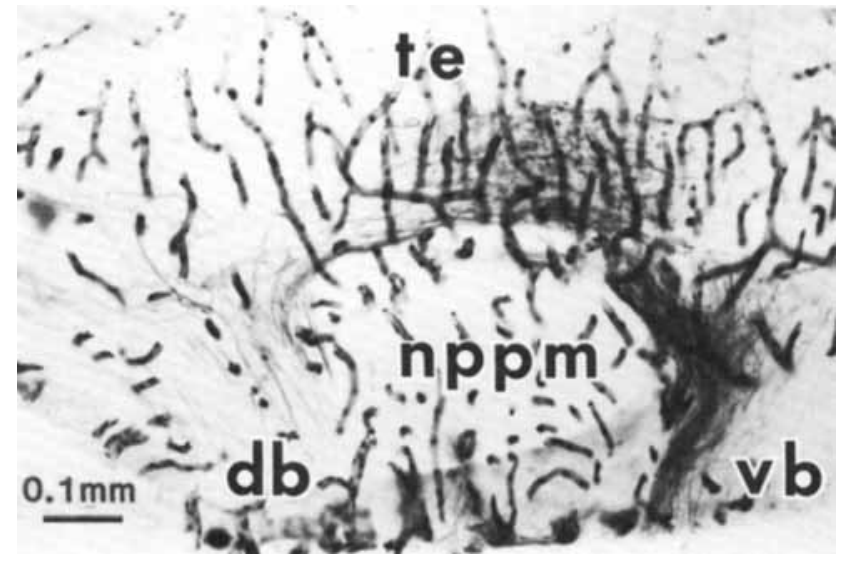

Fig. 12. Parasagittal section through the tectum (te) and nppm. A tem poral sector was labeled in the contralateral retina. Labeled axons curve around nppm in both the ventral (vb) and dorsal brachia (db) from which they exit. Rostral is down, ventral to the right.

4. The rearrangement of axons in the tract leads to a new stratification according to $\theta$ that anticipates the order of exit of the axons into the tectum.

Each of these points will be discussed in turn.

\section{Differential spread: $r$ vs. $\theta$}

The difference in the spread functions of axons of common $r$ and $\theta$ provides an explanation for the paradox stated in the beginning of this paper: If both $\theta$ and $r$ are mapped in the pathway, why do applications of HRP to the intraorbital nerve always backfill annuli and never sectors (Rusoff and Easter, '80)? We attribute this to the differential dispersion. The more tightly packed axons of common $r$ are likely to be labeled as a group; this is much less probable for the scattered axons of common $\theta$

The dispersion of axons of common $\theta$ in the optic nerve has been reported in other animals, as well: Xenopus (Fawcett, '81), Rana (Reh et al., '83; Scalia and Arango, '83), and chick (Ehrlich and Mark, '84).

The constancy of the spread function of axons of common $r$, contrasted with the increase in this function for axons of common $\theta$, indicates that the organizational unit of the goldfish optic pathway is the isochronic group of axons. The cause of this difference between the two spread functions is presently unknown, but we suggest a pair of speculative explanations, both involving cell adhesion molecules.

If all new axons, irrespective of the value of $\theta$ associated with each, were mutually adhesive, and equally so, then much of what we have observed would follow. According to this "one-factor hypothesis," retinotopic order in the optic nerve is a consequence of the spatiotemporal pattern of retinal growth. Axons of common $r$ would course together because they were all new simultaneously, and therefore adhered to one another. The fact that they shared a common value of $r$ would be an epiphenomenon, a consequence of the highly ordered retinal growth. At any time, there would be only two classes of axons-old and new-and when an axon was no longer new, it would be indistinguishable from others that might be much older. The mutual affinity of new axons would explain why growth cones avoid axonfree regions of the inner retina to grow along bundles of other recently formed axons (Easter et al., '84). The $\Theta$-group would be tightly clustered near the optic nerve head as a consequence of the spokelike pattern of axons in the retina (Easter et al., '84). More centrally, with these mechanical constraints removed, and given (by hypothesis) the absence of $\theta$-specific adhesion, axons of varying $\theta$ would disperse within the isochronic bundles of new axons, in a sort of random walk within the r-group. The neural cell adhesion molecule (N-CAM) (Edelman, '83) is an obvious candidate to mediate the interaxonal adhesion, as antibodies to $\mathrm{N}$ CAM block the fasciculation of axons in vitro (Rutishauser et al., '78; Rutishauser, '84) and prevent fasciculation of chick optic axons in vivo (Thanos et al.,'84).

An alternative explanation for the central increase in dispersion comes from another observation of N-CAM. Schlosshauer et al. ('84) have shown, in the chick embryo, that new retinal ganglion cell axons express a sialic-acidpoor form of N-CAM in the retina, but a sialic-acid-rich form in the nerve. The sialic-acid-poor form mediates stronger adhesion (Hofman and Edelman, '83). Strong adhesion might initially stabilize the order according to $\theta \mathrm{im}$ posed on the outgrowing axons by the growth pattern within the retina, while a decrease in adhesion would facilitate the exchange of neighbors in the nerve.

In contrast to what we believe is a passive spread of axons in the nerve, the reduction in the spread of the O-group in the tract is probably attributable to more active interactions between the axons and their non-axonal surroundings. If these surroundings expressed $\theta$-specific landmarks, so that axons from particular retinal sectors sought to occupy particular locations in the tract, then they would reorder and cluster as we have observed. The glial environment is known to change in the vicinity of the reordering (Scholes, '81; Levine et al., '85; Maggs and Scholes, '86), and is therefore a good candidate for the location of the hypothetical landmarks. This is essentially Sperry's chemoaffinity hypothesis (Sperry, '63), but restricted to the tract. Such a restriction is consistent with recent work in the visual system of Xenopus (Fawcett and Gaze, '82; Taylor et al., '85).

None of our observations required $\theta$-specific interactions between axons. Bonhoeffer and Huf ('85) have elegantly demonstrated such interactions between chick retinal axons, in vitro. Their approach removed virtually all other sources of interaction, with clear results. It is possible that similar interactions occurred in fish but were masked in vivo by the other, stronger, forces between axons and their non-axonal environment, and between axons of similar age.

Before leaving the subject of the clustering of axons by age, it seems advisable to respond to some criticisms of this idea from Springer and Mednick ('85a,b, '86b,c). Various observations have led these authors to question the idea that axons of the same age run together. Without disputing their observations, many of which are well documented, we believe that the results of this paper and earlier ones (Scholes, '79; Rusoff and Easter, '80; Easter et al. '81, '84; Stuermer and Easter, ' $84 \mathrm{~b}$ ) make it very clear that at all levels of the pathway, axons of the same age do run together. This is clearest near the optic nerve head (Fig. 2) and in the tract (Figs. 6-11, 13), where the bundle is stripshaped in cross section. None of these observations are in dispute. The source of the disagreement seems to be the term "fascicle," which Easter and his collaborators have used to mean a group of axons coursing together. Such usage is in keeping with the definition found in a medical dictionary: "A small bundle or cluster, chiefly of nervous or muscular fibers ..." (Arey et al., '60), and in fact agrees 

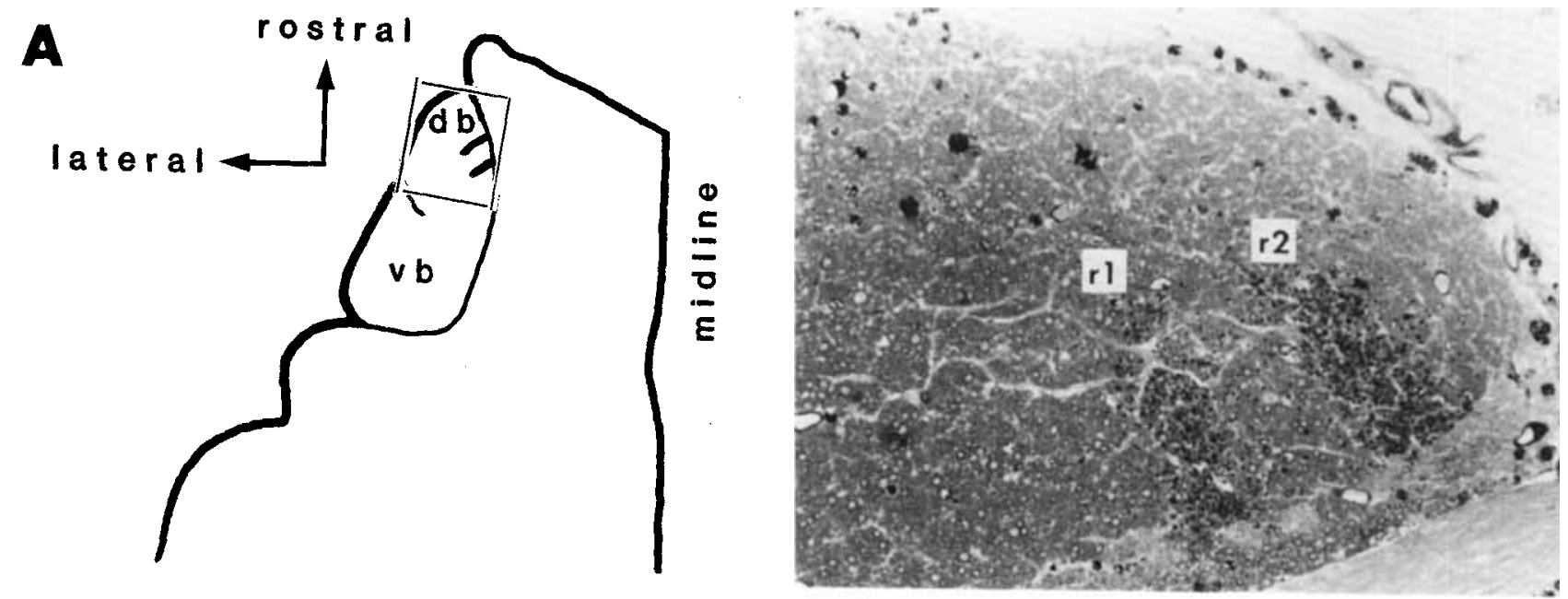

B

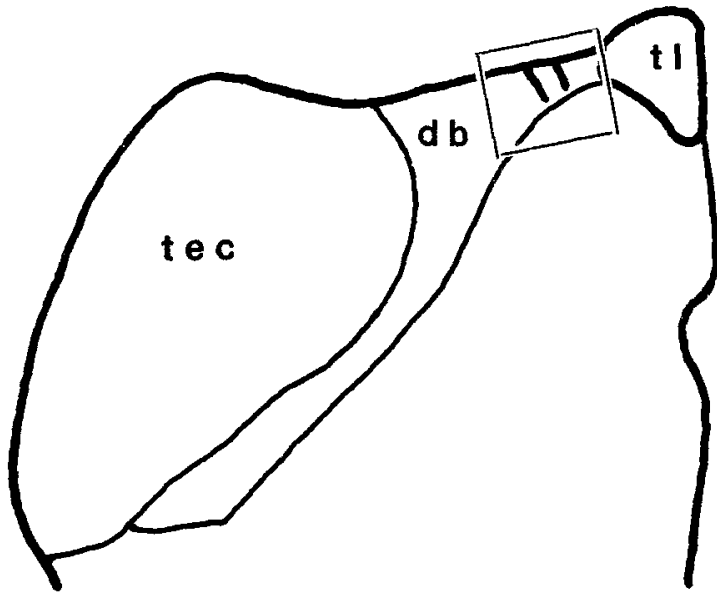

C

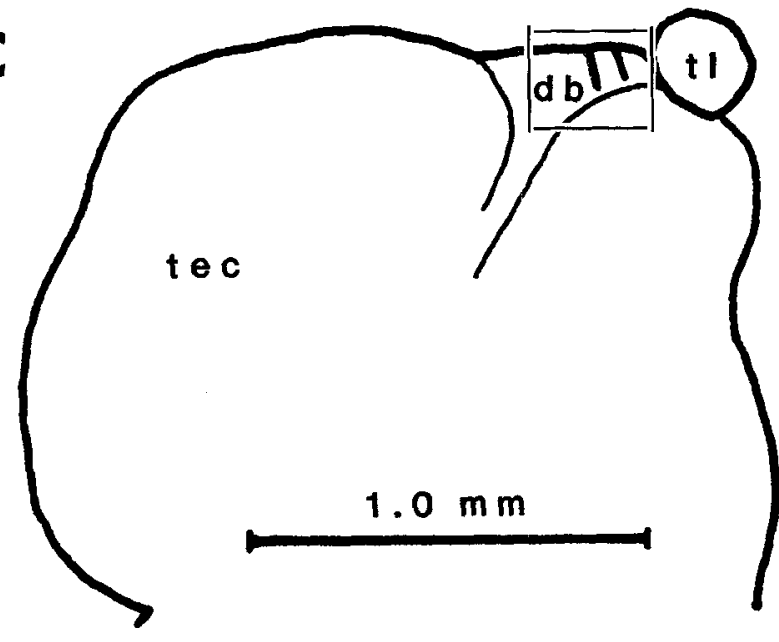

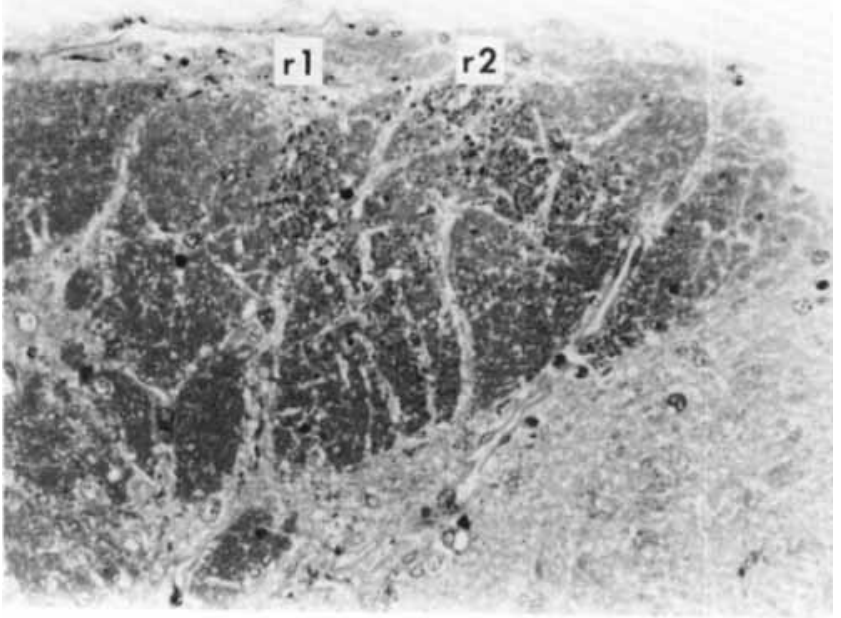

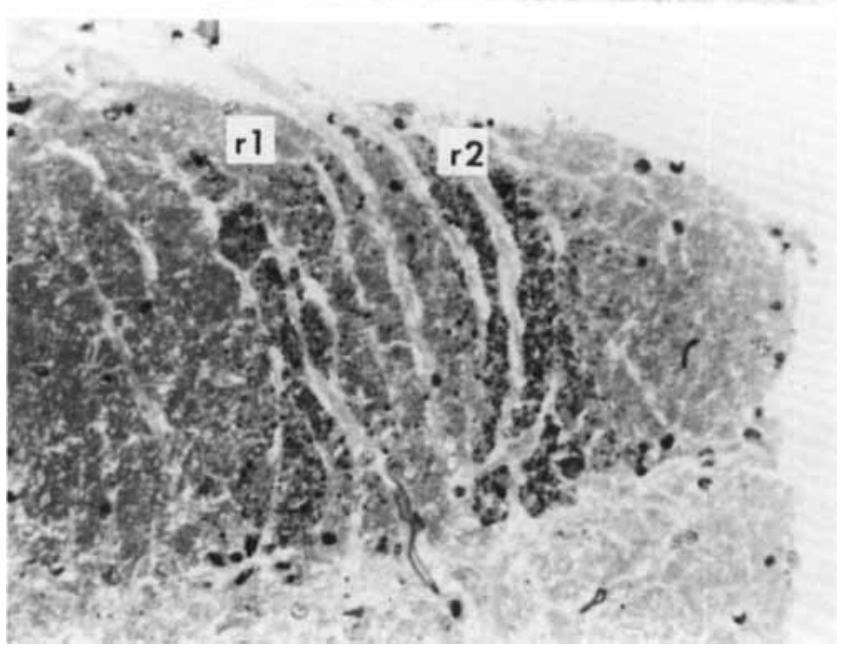

Fig. 13. A series of 3 semithin sections illustrating the transition of two r-bands in the tract into tectal fascicles. The region illustrated in each micrograph is indicated (box) in the accompanying camera lucida tracing. The corresponding retina is illustrated in Figure $11 \mathrm{C}$. Magnification as indicated in $\mathrm{C}$. tec, tectum; tl, torus longitudinalis; $\mathrm{db}$, dorsal brachium; $\mathrm{vb}$ ventral brachium.
A. Tract ( $t 1)$ The $r$-bands originate from peripheral and central retina ( 11 and $\mathrm{r} 2$, respectively). $\mathrm{B}$. Central to nppm $(\mathrm{t} 3)$, as the brachium runs medially along the tectum. C. About $100 \mu \mathrm{m}$ more caudally than B. 

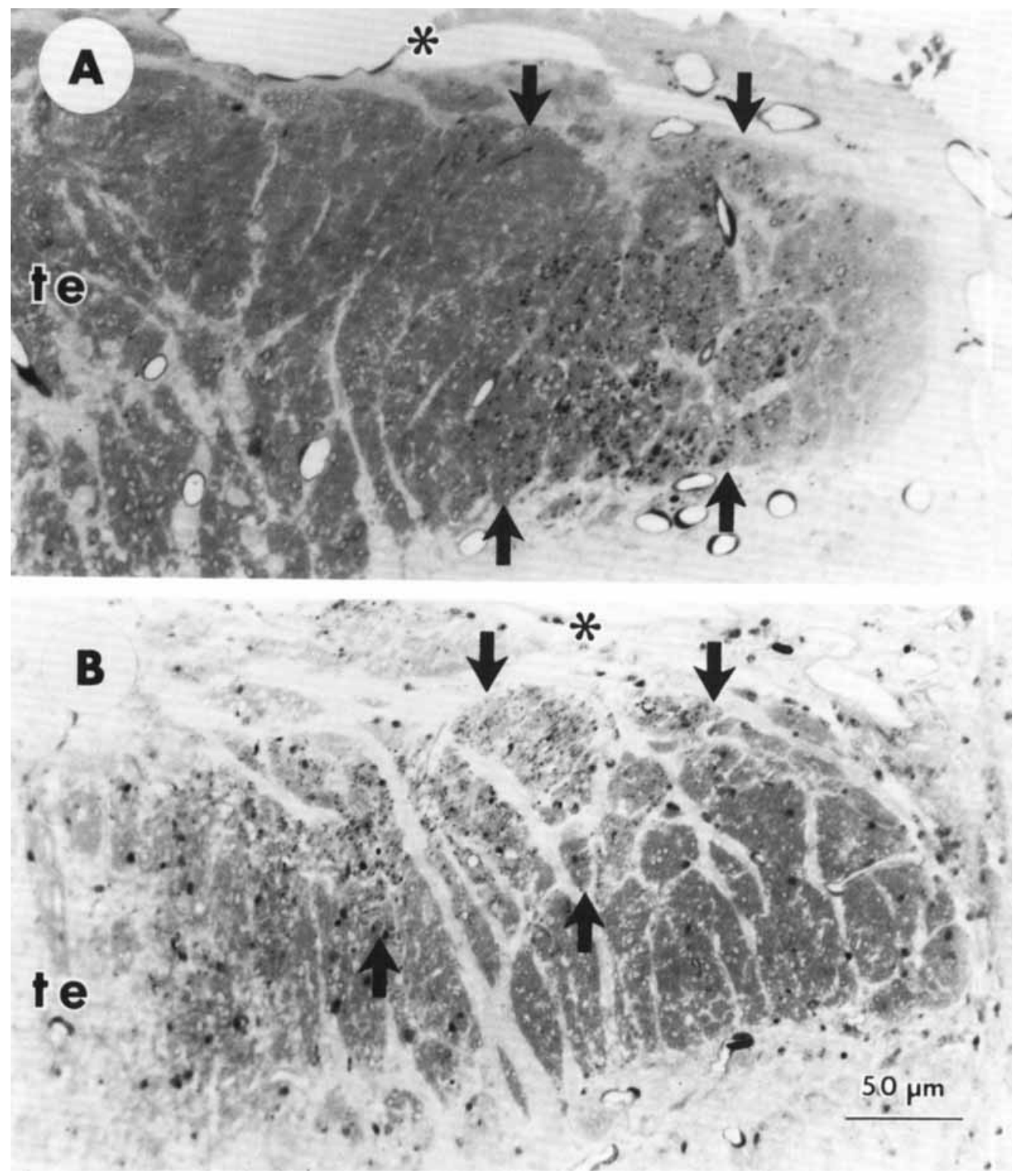

Fig. 14. Two semithin sections through the brachium as it runs along the medial edge of the tectum (t3). Same orientation as Figure 13. Asterisks mark pial surface. A. Labeled nasal retinal axons are concentrated deeply

with one of Springer and Mednick's definitions (" . . fascicle, [i.e., form a small bundle]" Springer and Mednick, '85a, p. 249). The dispute must therefore originate in either the limits of "small" or the shape of the "bundle." It seems to us that a subgroup of a nerve warrants being called "small," and a group of axons that, in cross section, is strip-shaped can justifiably be called a "bundle." The several published statements by Springer and Mednick do not clarify which if either of these interpretations is in dispute. In summary, the positions of the axons are not in dispute, only the words to describe them.

\section{Orthogonal mapping of $\mathbf{r}$ and $\theta$}

The organization of the map in the goldfish optic pathway is essentially similar to that of cichlid fish (Scholes, '79), but spread across the whole width of the brachium (between arrows). B. Labeled ventral retinal axons are confined to the superficial half (between arrows). even though the two dimensions are less distorted in cichlids. The origin of this order can be traced to the spatiotemporal pattern of the growth of the retina and the new axons. The similarities between the two kinds of fish are more striking than the differences, as should be evident in the next paragraph.

Sectoral order in the pathway is a consequence of the direct outgrowth of axons toward the retinal exit (Scholes, '79; Easter et al., '84), which brings new axons into immediate contact with others of similar $\theta$. Annular order in the pathway results because axons from successive generations of ganglion cells always grow along the innermost (vitread) surface of the optic fiber layer to join the nerve head (Scholes, '79; Easter et al., '84). In cichlid the optic nerve head is a dorsoventrally oriented slit and new axons are 
A

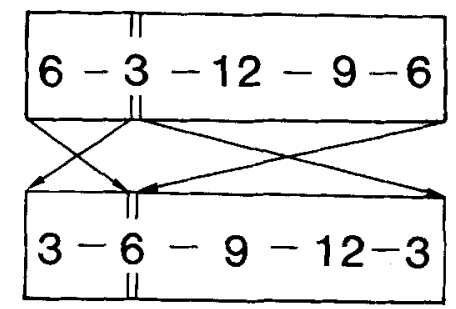

near

chiasm

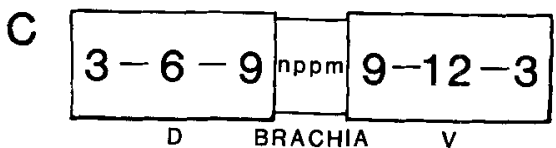

Fig. 15. A model illustrating the sectoral map at three levels of the optic pathway (right eye to left tectum). The numbers indicate the clock-face positions of the axons centered there. Rostrodorsal left, lateral up. A. Distal tract (near chiasm). The neighbor relationships are as they were at the optic nerve head. B. Proximal tract ( $\mathrm{t} 1$ ). Axons have rearranged (arrows) and the discontinuity in the representation of $\theta$, previously at the 6 o'clock radius, is now at the 3 o'clock radius. C. Brachia (t2). Axons of dorsal and ventral hemiretinal origin are separated by nppm.

added only at its ventral extreme. As a consequence of the continuing addition of new axons, the nerve head lengthens. This results, without further transformation, in a ribbon-shaped nerve, with $\mathrm{r}$ and $\theta$ laid down along the long and short axes, respectively (Scholes, '79). In goldfish the nerve head is ring-shaped, and centered on the ophthalmic artery; groups of new axons are added as annuli adjacent to this artery. As the nerve exits the eye, the vessel moves from the center toward the ventral pole of the nerve, and eventually the annulus is split and the new axons are brought to the surface of the nerve (Bunt, '82; Easter et al., '84). This results in an arrangement topologically similar to the ribbon in cichlids, but the two axes have about the same length. The most striking difference between the two nerves is the relative disorder, particularly intraorbitally, in the goldfish. We have no explanation for this, beyond noting that it presumably results from events secondary to the initial axonal outgrowth, since new generations of axons in goldfish, as in cichlids, course next to their immediate predecessors.

The polar coordinate and "chronotopic" (Dawnay, '79) organization of the optic nerve is obvious in those animals with appositional addition of ganglion cells over a long time, such as fish (Mueller, '52; Johns, '77) and amphibia (Straznicky and Gaze, '71; Jacobson, '76). In mammals, there is a centroperipheral gradient of retinal proliferation, but the addition of new ganglion cells is not exclusively appositional (Sidman, '61; Walsh et al., '83; Walsh and Polley, '85). Moreover, the period of ganglion cell production is much briefer than the years taken by fish and amphibians, and this brevity tends to mask the spatiotemporal gradient. One possibly exceptional mammal is the ferret, whose optic nerve is crudely ordered chronotopically (Walsh, '86). It remains to be seen if the retinal development is more strongly centroperipherally organized than that of the cat. These species differences are consistent with our suggestion above that new axons tend to stick together. When retinal development is spatiotemporally ordered, as in fish, frogs, and possibly in ferrets, the new axons have all been produced at nearby sites. When this order is lacking, new axons may originate nearly anywhere in the retina, and the retina-nerve map would be scrambled (Hubel and Wie-

sel, '60; Horton et al., '79; James and Bunt, '85; see also Williams and Rakic, '85).

\section{Discontinuities in the map}

The initial discontinuity in the retina-nerve map is quite similar, despite superficial differences, in cichlids and goldfish. In cichlids, the mapping of $\theta$ along one axis of the rectangular nerve head requires the discontinuity that is provided by the persisting embryonic fissure that bisects the ventral quadrant (Scholes, '79). In goldfish, the initial mapping of the retinal circumference onto the annular optic nerve head does not require such a discontinuity (Bunt, ' 82 ; Easter et al., '84), but the exit of the ophthalmic artery breaks the annulus, and a topologically similar map is the result. In both fish, the discontinuity in the retina correlates with the location of the embryonic fissure (Easter et al., '81, '84). We suggest that the location of the discontinuity is a trivial consequence of retinal morphogenesis in both fish.

In contrast, the establishment of a new discontinuity-at the nasal pole of the retina-requires an explanation of a different sort. The apparently purposive shifts of the axons between the chiasm and nppm (Fig. 6, and Fig. 2E of Easter et al., ' 81 ) imply an active process. The shift of the discontinuity from 6 o'clock to 3 o'clock reunified axons from neighboring sites on the ventral radius, and separated axons from neighboring sites on the nasal radius. Figure 15, a summary diagram, illustrates cross sections taken at three different levels of the optic pathway: near the chiasm, in the proximal tract ( $t 1)$, and in the brachia (t2). The numbers indicate the centers of the distributions of axons originating from the clock-face positions given by the numbers. It will be recalled that axons from a sector of ganglion cells dispersed fairly widely; so, for example, the region in the dorsal brachium labeled " 6 " contains some but not all of the ventral axons and contains axons from 5 o'clock and 7 o'clock as well.

The split of the tract at nppm may reflect either an active choice by the axons or simply the "momentum" of axons already in file, which encounter a mechanical barrier $(\mathbf{F u}$ jisawa, '81; Silver, '84). The latter "passive" explanation is plausible, since the more distal reordering (Fig. 5B,C) anticipates the separate representations of the ventral and dorsal hemiretinae in the two brachia. But there is support for the "active" alternative from studies of regenerating axons in which some regenerates that were oriented toward the "incorrect" brachium corrected their trajectory (goldfish: Stuermer and Easter, '84a; Xenopus: Fawcett and Gaze, '82; Gaze and Fawcett, '83). These same experiments showed that other regenerates failed to make corrections and entered the wrong path. The fact that more axons make mistakes in regeneration than in development suggests that both local cues and fiber order play a role in the initial development, at least in the tract.

Optic axons have been shown to reorder at the transition from nerve to tract in several vertebrates (fish: Scholes, '79; Bunt, '82; Rusoff, '84; Springer and Mednick, '86b; this paper; amphibians: Fawcett, '81; Reh et al., '83; Scalia and Arango, '83; chick: Ehrlich and Mark, '84; and mammals: Walsh and Guillery, '84; Walsh, '86). This is particularly evident in studies of the retinal projections to diencephalic targets (Fraley and Sharma, '84, '85; Presson et al., '85; Springer and Mednick, '85a). Axons leave the main (marginal) optic tract at the diencephalon, evidence for the existence of guidance cues in that region. But the cues do not 
Fig. 16. A. A model illustrating the organization of the optic tract and the dorsal brachium. The approximate orientation is given only for the dorsal brachium. Not drawn to scale. The unitary tract is shown as if lifted away from the diencephalon to illustrate its organization in cross section. It consists of stacked slabs of axons of common age $(1=$ oldest; $3=$ youngest; $2=$ intermediate). Within each slab, sectoral origin is represented by shading, $(\mathrm{N}=$ nasal; $\mathrm{V}=$ ventral; $\mathrm{T}=$ temporal; $\mathrm{D}=$ dorsal $)$. The tract splits at the level of nppm. In the dorsal brachium (representing the ventral hemiretina), temporal axons (T) are adjacent to nppm, nasal ones (N) far from it (Figs. 7, 8, 15). The youngest axons (3) lie rostrodorsally (adjacent to the pia), the oldest ones (1) deep (toward the diencephalon) (Fig. 11). Immediately central to nppm, the temporal axons ( $T$ ) split away from the other axons of their r-group to innervate most rostral tectum (small arrow) (Fig. 12). Ventral (V) and nasal (N) axons continue their course in the tectal portion of the brachium. Ascending dorsally and caudally the brachium twists and becomes aligned with the medial edge of the tectum. The oldest age slab (1) is immediately adjacent to the tectal neuropil (tec), the youngest (3) farthest from it (Fig. 13). Within each age slab ventral axons (V) are clustered dorsally (Fig. 14).

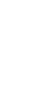
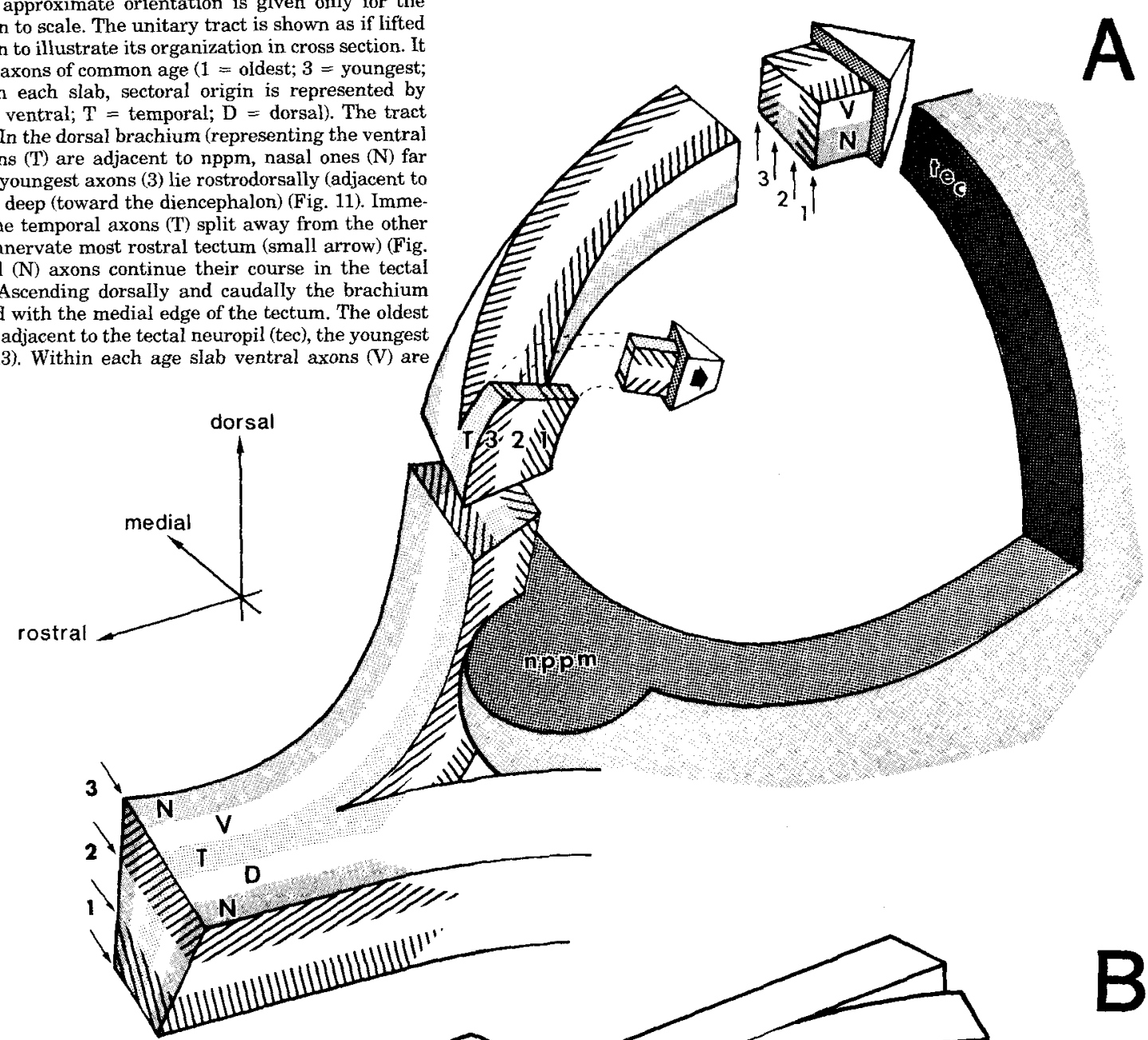

B. Continuous with the upper right arrow in A. A model illustrating the breakup of the dorsal brachium as it runs along the medial edge of the tectum. Orientation as in A. The retinal origins of the axons are shown in the lower right sketch. At the level illustrated, the temporalmost axons (stippled sector of retina) have already exited from the brachium (see A). The next most temporal axons exit next $(1 a, 2 a, 3 a)$. The more proximal departure of bundles $1 \mathrm{~b}$ and 1c illustrates the formation of a fascicle of axons in the tectal stratum opticum. At the time these axons first grew in, this was the outer boundary of the tectum (Stuermer and Easter, ' $84 \mathrm{~b}$ ). The illustration quantizes the axons into the cohorts, depending on three arbitrary divisions of $\mathrm{r}$ and $\theta$. This is for purposes of clarity only; the units of quantization, if any, are unknown. 
apparently affect the axons remaining in the tract, since the retina-tract map for these axons does not change. Apparently some retinal axons react differently to the cues than others.

\section{Fiber topography and the order of exit of axons into the tectum}

Previous work in goldfish (Stuermer and Easter, ' $84 \mathrm{~b}$ ) has demonstrated that successive generations of new retinal axons grow in the brachium and exit from it to enter the tectum in order-temporal axons first, nasal last-and terminate near their entry point. The tectum enlarges by adding a crescent of new cells along the dorsal, caudal, and ventral (but not the rostral) rims (Raymond and Easter, '83), and the axons that grew in the most central portion of the brachium, along the old tectal margin, are thus partly enveloped. New axons will grow around the new and enlarged tectal boundary. Thus the brachium, broad and unitary at the level of nppm, is thinned and unraveled by two related events. One is the departure, in temporonasal sequence, of axons of all generations (Stuermer and Easter, ' $84 \mathrm{~b})$. The other is the separation of generations of axons. Axons which at one time made up the tectal portion of the brachium are successively incorporated into the expanding tectum to form the fanlike radiation of fascicles of the tectal stratum opticum.

Our conception of these events, and of the resultant structure, is illustrated in Figure 16A, which shows the pathway from tract to the rostral brachium, and Figure 16B, which shows the more proximal unraveling of the brachium. At the level of the nppm, slabs of axons of similar $r$ are parallel to the pia and the newest axons are the most superficial. Just proximal to the site where the temporalmost axons of all ages exit to innervate the rostral tectum (see Fig. 12), the retina-brachium map changes orientation, so that the $r$-bands are perpendicular to the pia along one side, and parallel to it on another (see Fig. 13). In other words, the pial surface, which was gently curved and oriented parallel to the strip of new axons, becomes bent, and the $r$-bands continue to course parallel to that short edge (adjacent to the torus longitudinalis) and perpendicular to the longer edge (compare Fig. 13A,B). At this point, the dorsal brachium is trapezoidal in cross section, with the base adjacent to the tectum and the apex away from it. Future generations of axons will be added to the apex and therefore must enter the tectum from a substantial distance, the width of the brachium, which is a few hundred micrometers in the case of Figure 13B. Generations of older axons are lost from the base of the triangle as they form the fascicles of the stratum opticum (compare Figs. 13B,C, 16B).

The representation of sectoral origin within the optic tract and brachia is related to the order of exit (Fig. 16, this report; Bunt '82; Springer and Mednick, ' $85 \mathrm{~b}$ ). The temporonasal order of the exit matches the temporonasal stratification of the axons in the brachia. Those with the temporalmost address (closest to 9 o'clock in the cohort of ventral hemiretinal axons) are always closest to either nppm (in the tract) or the superficial pial boundary (in the brachium). We suppose that the axons exit along this pial surface, and this suggests that guidance cues might be available to them in that region. Furthermore, we suggest that local guidance cues, stratification, and proximity to the pia all contribute to the orderly exit of axons from the brachium into the tectum and ultimately to the formation of the retinotectal map. It has been argued elsewhere (Easter et al., '85) that multiple factors probably control orderly axonal outgrowth in most nervous systems.

\section{ACKNOWLEDGMENTS}

We thank Drs. Peter Hitchcock and Pamela A. Raymond for helpful discussions, Celeste Malinoski for technical help, Margaret Madouse for secretarial assistance, and David Bay for photographic assistance. This work was supported by grant EY-00168 to S.S.E. and by a grant from the Janggen-Poehn Foundation to R.B.

\section{LITERATURE CITED}

Adams, J.C. (1981) Heavy metal intensification of DAB-based HRP reaction product. J. Histochem. Cytochem. 26:775.

Arey, L.B., W. Burrows, J.P. Greenhill, and R.M. Hewitt (1960) Dorland's Illustrated Medical Dictionary. 23rd Ed. Philadelphia: W.B. Saunders.

Attardi, D.G., and R.W. Sperry (1963) Preferential selection of central path. ways by regenerating optic fibers. Exp. Neurol. 7:46-64.

Bernhardt, R., and S.S. Easter (1985) Age and sectoral origin of ganglion cell axons are mapped on two orthogonal axes in the optic pathway of goldfish. Soc. Neurosci. Abstr. 11:585.

Bonhoeffer, F., and J. Huf (1985) Position dependent properties of retinal axons and their growth cones. Nature 315:409-410.

Braford, M.R., and R.G. Northcutt (1983) Organization of the diencephalon and pretectum in ray-finned fishes. In R.E. Davis and R.G. Northcutt (eds): Fish Neurobiology, Vol. 2. Ann Arbor: University of Michigan Press, pp. 117-163.

Bunt, S.M. (1982) Retinotopic and temporal organization of the optic nerve and tracts in the adult goldfish. J. Comp. Neurol. 206:209-226.

Bunt, S.M., and T.J. Horder (1983) Evidence for an orderly arrangement of optic axons in the optic nerves of the major nonmammalian vertebrate classes. J. Comp. Neurol. 213:94-114.

Dawnay, N.A.H. (1979) "Chronotopic" organisation of goldfish optic pathway. J. Physiol. (Lond.) 296:13-14.

Easter, S.S. (1985) The continuous formation of the retinotectal map in goldfish, with special attention to the role of the axonal pathway. In G.M. Edelman, W.E. Gall, and W.M. Cowan (eds): Molecular Bases of Neural Development. New York: Wiley and Sons, pp. 429-452.

Easter, S.S., B. Bratton, and S.S. Scherer (1984) Growth related order of the retinal fiber layer in goldfish. J. Neurosci. 4:2173-2190.

Easter, S.S., D. Purves, P. Rakic, and N.C. Spitzer (1985) The changing view of neural specificity. Science 230:507-511.

Easter, S.S., A.C. Rusoff, and P.E. Kish (1981) The growth and organization of the optic nerve and tract in juvenile and adult goldfish. J. Neurosci. 1:793-811.

Edelman, G.M. (1983) Cell adhesion molecules. Science 219:450-457.

Ehrlich, D., and R. Mark (1984) The course of axons of retinal ganglion cells within the optic nerve and tract of the chick (Gallus gallus).J. Comp. Neurol. 223:583-591.

Fawcett, J.W. (1981) How axons grow down the Xenopus optic nerve. J. Embryol. Exp. Morphol. 65:219-233.

Fawcett, J.W., and R.M. Gaze (1982) The retinotectal fiber pathways from normal and compound eyes in Xenopus. J. Embryol. Exp. Morphol. 72:19-37.

Fraley, S.M., and S.C. Sharma (1984) Topography of retinal axons in the diencephalon of goldfish. Cell. Tissue Res. 238:529-538.

Fraley, S.M., and S.C. Sharma (1985) Retinal origin of the fasciculus medialis tractus opticus in adult goldfish. Brain Res. 337:392-395.

Fujisawa, H, (1981) Retinotopic analysis of fiber pathways in the regenerating retinotectal system of the adult newt Cynops pyrrhogaster. Brain Res. 206:27-37.

Gaze, R.M. (1970) The Formation of Nerve Connections. London and New York: Academic Press.

Gaze, R.M., and J.W. Fawcett (1983) Pathways of Xenopus optic fibers regenerating from normal and compound eyes under various conditions. J. Embryol. Exp. Morphol. 73:17-38.

Hofman, S., and G.M. Edelman (1983) Kinetics of homophilic binding of $\mathrm{E}$ and $A$ forms of the neural cell adhesion molecule. Proc. Natl. Acad. Sci. USA 80:5762-5766.

Horder, T.J, and K.A.C. Martin (1978) Morphogenetics as an alternative to chemospecificity in the formation of nerve connections. In A.S.G. Curtis 
(ed): Sym. Soc. Exp. Biol. 32. Cell-Cell Recognition. Cambridge: Cam bridge University Press, pp. $275-358$.

Horton, J.C., M.M. Greenwood, and D.H. Hubel (1979) Non-retinotopic arrangement of fibers in the cat optic nerve. Nature 282:720-722.

Hubel, D.H., and T.N. Wiesel (1960) Receptive fields of optic nerve fibers in the spider monkey. J. T"1ysiol. (Lond.) 154:572-580.

Jacobson, M. (1976) Histogenesis of retina in the clawed frog with implications for the pattern of development of retinotectal connections. Brain Res. 103:541-545.

James, J.L., and S.M. Bunt (1985) Optic fiber arrangements on the retina surface of an animal with an ordered optic nerve and an animal with a disorderly optic nerve. Soc. Neurosci. Abstr. 11:222.

Johns, P.R. (1977) Growth of the adult goldfish eye. III. Source of new retinal cells. J. Comp. Neurol. 176:343-358.

Levine, R.L., A. Tsang, and C. Verdone-Smith (1985) Two populations of astrocytes in the goldfish central nervous system. Soc. Neurosci. Abstr. 11:84.

Maggs, A., and J.H. Scholes (1986) Glial domains and nerve fiber patterns in the fish retinotectal pathway. J. Neurosci. 6:424-438.

Mueller, H. (1952) Bau and Wachstum der Netzhaut des Guppy (Lebistes reticulatus) Zool. Jb. 63:275-324.

Presson, J., R.D. Fernald, and M. Max (1985) The organization of retinal projections to the diencephalon and pretectum in the cichlid fish $H a p$ lochromis burtoni. J. Comp. Neurol. 235:360-374.

Raymond, P.A., and S.S. Easter (1983) Postembryonic growth of the optic tectum in goldfish. I. Location of germinal cells and numbers of neurons produced. J. Neurosci. 3:1077-1091.

Reh, T.A., E. Pitts, and M. Constantine-Paton. (1983) The organization of the fibers in the optic nerve of normal and tectum-less Rana pipiens. J. Comp. Neurol. 218:282-296.

Rusoff, A.C. (1984) Paths of axons in the visual system of perciform fish and implications of these paths for rules governing axonal growth. J. Neurosci. 4:1414-1428.

Rusoff, A.C., and S.S. Easter (1980) Order in the optic nerve in goldfish. Science 208:311-312.

Rutishauser, U. (1984) Developmental biology of a neural cell adhesion molecule. Nature 310:549-554.

Rutishauser, U., W.E. Gall, and G.M. Edelman (1978) Adhesion among neural cells of the chick embryo. IV. Role of the cell surface molecule CAM in the formation of neurite bundles in cultures of spinal ganglia. J. Cell Biol. 79:382-393.

Scalia, F., and V. Arango (1983) The anti-retinotopic organisation of the frog's optic nerve. Brain Res. 266:121-126.

Schlosshauer, L., U. Schwarz, and U. Rutishauser (1984) Topological distribution of different forms of neural cell adhesion molecule in the developing chick visual system. Nature 310:141-143.

Scholes, J.H. (1979) Nerve fibre topography in the retinal projection to the tectum. Nature 278:620-624.

Scholes, J.H. (1981) Ribbon optic nerves and axonal growth patterns in the retinal projection to the tectum. In D.R. Garrod and J.D. Feldman (eds): Development in the Nervous System, Fifth Symposium of the British
Society for Developmental Biology. Cambridge: Cambridge University Press, pp.185-214.

Sidman, R.L. (1961) Histogenesis of mouse retina studied with thymidine${ }^{3}$ H. In G.K. Smelser (ed): The Structure of the Eye. New York: Academic Press, pp. 487-506.

Silver, J. (1984) Studies on factors that govern directionality of axonal growth in the embryonic optic nerve and at the chiasm of mice. J. Comp. Neurol. 223:238-251.

Sperry, R.W. (1963) Chemoaffinity in the orderly growth of nerve fiber patterns and connections. Proc. Natl. Acad. Sci. USA 50:703-710.

Springer, A.D., and A.S. Mednick (1985a) Topography of the retinal projection to the superficial pretectal parvicellular nucleus of goldfish: A cobaltous-lysine study. J. Comp. Neurol. 237:239-250.

Springer, A.D., and A.S. Mednick (1985b) Topography of the goldfish optic tracts: Implications for the chronological clustering model. J. Comp. Neurol. 239:108-116.

Springer, A.D., and A.S. Mednick (1986a) Relationship of ocular pigmentation to the boundaries of the dorsal and ventral retina in a nonmammalian vertebrate. J. Comp. Neurol. 245:74-82.

Springer, A.D., and A.S. Mednick (1986b) Retinotopic and chronotopic or ganization of goldfish retinal ganglion cell axons throughout the optic nerve. J. Comp. Neurol. 247:221-232.

Springer, A.D., and A.S. Mednick (1986c) Simple and complex retinal ganglion cell axonal rearrangements at the optic chiasm. J. Comp. Neurol. 247:233-245.

Straznicky, K., and R.M. Gaze (1971) The growth of the retina in Xenopus laevis: An autoradiographic study. J. Embryol. Exp. Morphol. 26:67-79.

Stuermer, C.A.O., and S.S. Easter (1984a) A comparison of the normal and regenerated retinotectal pathways of goldfish. J. Comp. Neurol. 223:5776.

Stuermer, C.A.O., and S.S. Easter (1984b) Rules of order in the retinotectal fascicles of goldfish. J. Neurosci. 4:1045-1051.

Taylor, J.S.H., D.J. Willshaw, and R.M. Gaze (1985) The distribution of fibres in the optic tract after contralateral translocation of an eye in Xenopus. J. Embryol. Exp. Morphol. 85:225-238.

Thanos, S., F. Bonhoeffer, and U. Rutishauser (1984) Fiber-fiber interactions and tectal ues influence the development of the chicken retinotectal projection. Proc. Natl. Acad. Sci. USA 81:1906-1910.

Walsh, C. (1986) Age-related fiber order in the ferret's optic nerve and optic chiasm. J. Neurosci., 6:1635-1642.

Walsh, C. and R.W. Guillery (1984) Fiber order in the pathways from the eye to the brain. Trends Neurosci, 7:208-211.

Walsh, C., and E.H. Polley (1985) The topography of ganglion cell production in the cat's retina. $d$. Neurosci. 5:741-750.

Walsh, C., E.H. Polley, T.L. Hickey, and R.W. Guillery (1983) Generation of cat retinal ganglion cells in relation to central pathways. Nature 302:611-614.

Williams, R.W. and P. Rakic (1985) Dispersion of growing axons within the optic nerve of the embryonic monkey. Proc. Natl. Acad. Sci. USA 2:39063910. 